\title{
Genetic resistance to JAK2 enzymatic inhibitors is overcome by HSP90 inhibition
}

\section{Citation}

Weigert, Oliver, Andrew A. Lane, Liat Bird, Nadja Kopp, Bjoern Chapuy, Diederik van Bodegom, Angela V. Toms, et al. 2012. Genetic resistance to JAK2 enzymatic inhibitors is overcome by HSP90 inhibition. The Journal of Experimental Medicine 209(2): 259-273.

\section{Published Version}

doi:10.1084/jem.20111694

\section{Permanent link}

http://nrs.harvard.edu/urn-3:HUL.InstRepos:10465035

\section{Terms of Use}

This article was downloaded from Harvard University's DASH repository, and is made available under the terms and conditions applicable to Other Posted Material, as set forth at http:// nrs.harvard.edu/urn-3:HUL.InstRepos:dash.current.terms-of-use\#LAA

\section{Share Your Story}

The Harvard community has made this article openly available.

Please share how this access benefits you. Submit a story.

\section{Accessibility}




\section{Genetic resistance to JAK2 enzymatic inhibitors is overcome by HSP90 inhibition}

Oliver Weigert, ${ }^{1}$ Andrew A. Lane, ${ }^{1}$ Liat Bird, ${ }^{1}$ Nadja Kopp, ${ }^{1}$

Bjoern Chapuy, ${ }^{1}$ Diederik van Bodegom, ${ }^{1}$ Angela V. Toms, ${ }^{2,7}$

Sachie Marubayashi, ${ }^{5}$ Amanda L. Christie, ${ }^{4}$ Michael McKeown, ${ }^{1}$

Ronald M. Paranal, ${ }^{1}$ James E. Bradner, ${ }^{1}$ Akinori Yoda, ${ }^{1}$ Christoph Gaul, ${ }^{6}$

Eric Vangrevelinghe, ${ }^{6}$ Vincent Romanet, ${ }^{6}$ Masato Murakami, ${ }^{6}$ Ralph Tiedt, ${ }^{6}$

Nicolas Ebel, ${ }^{6}$ Emeline Evrot, ${ }^{6}$ Alain De Pover, ${ }^{6}$ Catherine H. Régnier, ${ }^{6}$

Dirk Erdmann, ${ }^{6}$ Francesco Hofmann, ${ }^{6}$ Michael J. Eck, ${ }^{2,7}$ Stephen E. Sallan, ${ }^{4}$

Ross L. Levine, ${ }^{5}$ Andrew L. Kung, ${ }^{3,4,8}$ Fabienne Baffert, ${ }^{6}$

Thomas Radimerski, ${ }^{6}$ and David M. Weinstock ${ }^{1,8}$

Departments of ${ }^{1}$ Medical Oncology, ${ }^{2}$ Cancer Biology, ${ }^{3}$ Pediatric Oncology, and the ${ }^{4}$ Lurie Family Imaging Center, Dana-Farber Cancer Institute, Boston, MA 02115

${ }^{5}$ Human Oncology Pathogenesis Program and Leukemia Service, Memorial Sloan-Kettering Cancer Center, New York, New York 10065

${ }^{6}$ Novartis Institute for Biomedical Research, CH-4057 Basel, Switzerland

${ }^{7}$ Department of Biological Chemistry and Molecular Pharmacology and ${ }^{8}$ Department of Biological and Biomedical Sciences, Harvard Medical School, Boston, MA 02115

Enzymatic inhibitors of Janus kinase 2 (JAK2) are in clinical development for the treatment of myeloproliferative neoplasms (MPNs), B cell acute lymphoblastic leukemia (B-ALL) with rearrangements of the cytokine receptor subunit cytokine receptor-like factor 2 (CRLF2), and other tumors with constitutive JAK2 signaling. In this study, we identify G935R, Y931C, and E864K mutations within the JAK2 kinase domain that confer resistance across a panel of JAK inhibitors, whether present in cis with JAK2 V617F (observed in MPNs) or JAK2 R683G (observed in B-ALL). G935R, Y931C, and E864K do not reduce the sensitivity of JAK2-dependent cells to inhibitors of heat shock protein 90 (HSP90), which promote the degradation of both wild-type and mutant JAK2. HSP90 inhibitors were 100-1,000-fold more potent against CRLF2-rearranged B-ALL cells, which correlated with JAK2 degradation and more extensive blockade of JAK2/STAT5, MAP kinase, and AKT signaling. In addition, the HSP90 inhibitor AUY922 prolonged survival of mice xenografted with primary human CRLF2-rearranged B-ALL further than an enzymatic JAK2 inhibitor. Thus, HSP90 is a promising therapeutic target in JAK2-driven cancers, including those with genetic resistance to JAK enzymatic inhibitors.

CORRESPONDENCE

dweinstock@partners.org

OR

Thomas Radimerski:

thomas.radimerski@novartis.com

Abbreviations used: B-ALL, B cell acute lymphoblastic leukemia; CRLF2, cytokine receptorlike factor 2; EpoR,

erythropoietin receptor; GSEA, gene set enrichment analysis;

HSF, heat shock factor; HSP, heat

shock protein; JAK, Janus kinase;

JAKinh-1, JAK inhibitor-1; JH1,

JAK homology domain 1; MPN,

myeloproliferative neoplasm;

NSG, NOD.Cg-Prkde ${ }^{\text {sid }}$

Il2 $\mathrm{rg}^{\mathrm{tm} 1 \mathrm{Wjl}} / \mathrm{SzJ}$; RFU, relative

fluorescence unit; VF,

Ba/F3-EpoR/Jak2 V617F.
Janus kinase 2 (JAK2) is an intracellular tyrosine kinase that associates with the cytoplasmic domains of multiple cytokine receptors. Ligand binding by the receptor results in conformational changes that activate JAK2, resulting in phosphorylation of target proteins, including STATs and JAK2 itself (Ihle and Gilliland, 2007). More than $50 \%$ of myeloproliferative neoplasms (MPNs) harbor the activating JAK2 V617F mutation (Levine et al., 2005, 2007). In addition, a subset of B cell acute lymphoblastic leukemia (B-ALL) with rearrangements of cytokine receptor-like factor 2 (CRLF2) have activating JAK2 mutations that primarily involve R683 (Mullighan et al., 2009a;
Russell et al., 2009; Hertzberg et al., 2010; Yoda et al., 2010). Additional cases of CRLF2rearranged B-ALL lack JAK2 mutations but harbor a CRLF2 F232C or IL7R mutation (Yoda et al., 2010; Shochat et al., 2011) that promotes constitutive receptor dimerization and signaling through wild-type JAK2, which is analogous to the MPL W515L mutation observed in a subset of MPNs (Pikman et al., 2006).

( 2012 Weigert et al. This article is distributed under the terms of an AttributionNoncommercial-Share Alike-No Mirror Sites license for the first six months after the publication date (see http://www.rupress.org/terms). After six months it is
the available under a Creative Commons License (Attribution-Noncommercial-Share Alike 3.0 Unported license, as described at http://creativecommons.org/licenses/ by-nc-sa/3.0/). 
Constitutive signaling through wild-type JAK2 contributes to the proliferation of many other cancers, including myeloid malignancies (Najfeld et al., 2007; Wardrop and Steensma, 2009), B cell lymphomas (Green et al., 2010; Rui et al., 2010), and hormone receptor-/ERBB2-negative breast cancers (Marotta et al., 2011). Thus, JAK2 is emerging as an attractive target with broad therapeutic potential.

Multiple ATP-mimetic inhibitors of JAK2 are under development (Verstovsek, 2009). In patients with MPN, JAK2 inhibitors can reduce $J A K 2$ allele burden, spleen size, and constitutional symptoms (Pardanani et al., 2011; Verstovsek et al., 2011), but have not resulted in molecular remissions like those observed in patients treated with tyrosine kinase inhibitors for tumors with $A B L 1, B-R A F$, or C-KIT alterations (Druker et al., 2001; Joensuu et al., 2001; Flaherty et al., 2010). This observation could result from a lack of addiction to JAK2 signaling in MPNs, which is supported by the variable allele frequency of JAK2 V617F among malignant cells in most patients. In contrast with MPNs, CRLF2-rearranged B-ALL with JAK2 mutations appear to harbor the JAK2 mutation in essentially all leukemic cells (Mullighan et al., 2009b; Yoda et al., 2010), which may indicate more extensive addiction and therefore greater therapeutic benefit from inhibiting JAK2.

Among cancers dependent on tyrosine kinases, treatment with ATP-mimetic inhibitors has invariably resulted in the development of inhibitor resistance mutations (Engelman and Settleman, 2008). Using the novel JAK2 inhibitor NVP_BVB808 (BVB808), we recovered E864K, Y931C, and G935R mutations within the kinase domain of JAK2 that confer resistance to multiple JAK2 enzymatic inhibitors. In addition, we show that treatment with inhibitors of heat shock protein 90 (HSP90) can overcome all three resistance mutations and potently kill cells dependent on JAK2. Finally, we demonstrate that the HSP90 inhibitor NVP_AUY922 (AUY922) more potently suppresses JAK-STAT, MAP kinase, and AKT signaling than BVB808, which translates into prolonged survival in mice xenografted with human B-ALL.

\section{RESULTS}

\section{BVB808 is a selective JAK2 inhibitor with activity in vivo}

Inhibitors of JAK2 enzymatic activity offer potential therapeutic benefit for patients with malignant and nonmalignant diseases that have constitutive JAK2 signaling (Kiss et al., 2010). We assayed the activity of BVB808, a novel JAK2 inhibitor of the $\mathrm{N}$-aryl-pyrrolopyrimidine scaffold class (Fig. 1 A). BVB808 has 10-fold selectivity in vitro for JAK2 compared with JAK1, JAK3, or TYK2 (Fig. 1 B) and exhibited $>100$-fold selectivity for JAK2 in a kinase assay panel consisting of $66 \mathrm{Ser} / \mathrm{Thr} / \mathrm{Ty} /$ lipid kinases, with the exception of cABL1 $(40 \times)$, cABL1 T315I $(75 \times)$, ROCK2 $(70 \times)$, and

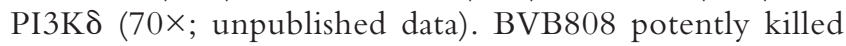
JAK2-dependent cell lines and MPL W515L-driven Ba/F3 cells, as well as FLT-3 ITD mutant MV4-11 cells, with halfmaximal growth inhibitory $\left(\mathrm{GI}_{50}\right)$ concentrations $\leq 60 \mathrm{nM}$ (Fig. 1 C). In contrast, modest growth inhibition was observed at the same concentrations in JAK3 A572V mutant CMK and $B C R-A B L 1$ rearranged K-562 cells (Fig. 1 C). BVB808 rapidly and potently blocked JAK2-dependent phosphorylation of STAT5 (pSTAT5) and induced PARP cleavage in JAK2 V617F-dependent MB-02 and SET-2 cells (Fig. 1, D-G). Inhibition of pSTAT 5 required an $\sim 10$-fold higher dose of BVB808 in CMK cells compared with MB-02 and SET-2 cells, consistent with the preferential activity against JAK2 (Fig. 1, D and E).

To determine the in vivo activity of BVB808, we used a bone marrow transplant model of Jak2 V617F-driven MPN. Bone marrow from BALB/c mice was transduced with Jak2 $\mathrm{V} 617 \mathrm{~F}$ and transplanted into congenic recipients. Upon development of polycythemia, mice were randomized to treatment with $50 \mathrm{mg} / \mathrm{kg}$ of either vehicle or BVB808 twice daily. After 3 wk of treatment, mice were sacrificed and assessed for pharmacodynamic and clinical endpoints. Compared with controls, BVB808-treated mice had reduced reticulocyte (mean \pm SEM; $0.7 \pm 0.1$ versus $0.4 \pm 0.10 \times 10^{12} /$ liter; $n=3-6$ ) and WBC counts $\left(19.9 \pm 3.0\right.$ versus $11.4 \pm 3.2 \times 10^{9} /$ liter; $n=3-6)$. BVB808 reduced bone marrow hypercellularity (Fig. $1 \mathrm{H}$ ), normalized spleen weight (Fig. $1 \mathrm{I}$ ), and suppressed pSTAT5 in both spleen and bone marrow (Fig. $1 \mathrm{~J}$ ).

\section{Point mutations in the JAK2 kinase domain confer resistance to JAK inhibitors}

Mutations in tyrosine kinases are a common cause of genetic resistance to enzymatic inhibitors (Engelman and Settleman, 2008). To identify resistance mutations in JAK2, we modified an approach that was previously applied to identify $B C R / A B L 1$ mutations that confer resistance to imatinib (Azam et al., 2003). Expression of CRLF2 with a JAK2 $\mathrm{R} 683 \mathrm{G}$ renders murine $\mathrm{Ba} / \mathrm{F} 3$ cells capable of growth in the absence of IL-3 (Mullighan et al., 2009a; Russell et al., 2009; Hertzberg et al., 2010; Yoda et al., 2010). We randomly mutagenized human JAK2 R683G cDNA and transduced the mutagenized cDNA library into $\mathrm{Ba} / \mathrm{F} 3$ cells expressing CRLF2 (Ba/F3-CRLF2; Fig. 2 A). The transduced population was selected in $1 \mu \mathrm{M}$ BVB808 in the absence of IL-3 (Fig. 2 A). Within 2-3 wk, multiple BVB808-resistant clones expanded from single cells. We sequenced the mutagenized JAK2 R683G cDNA from genomic DNA of individual BVB808-resistant clones and identified multiple clones with E864K, Y931C, or G935R mutations.

Even in the absence of a transforming oncogene, transduction of $\mathrm{Ba} / \mathrm{F} 3$ cells can occasionally result in individual clones that have escaped IL-3 independence through nonJAK2-mediated signaling. If this occurred, the surviving IL-3independent cells would be resistant to JAK2 inhibitors but not dependent on JAK2. Thus, we took three approaches to confirm that the cells expressing E864K, Y931C, or G935R in cis with a JAK2 gain-of-function allele are dependent on JAK2 function and resistant to enzymatic inhibitors. First, we recloned the mutations into human JAK2 R683G cDNA by site-specific mutagenesis and confirmed their ability to confer BVB808 resistance when expressed in combination with 
A<smiles>CC1CN(C(C)CC(C)(C)C)CC(C)N1</smiles>

E

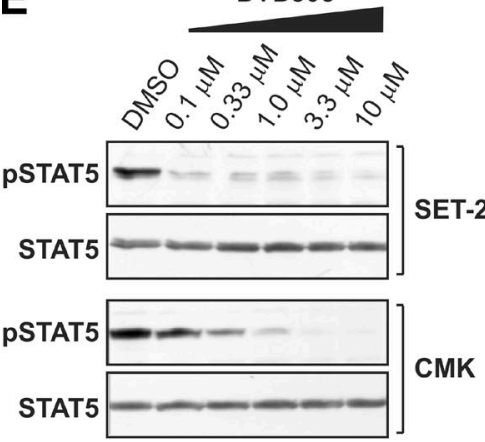

B $\quad$ IC50 (nM)

JAK1 $3.75 \pm 0.24$

JAK2 $0.35 \pm 0.03$

JAK3 $2.66 \pm 0.10$

TYK2 $3.32 \pm 0.44$
C

$\begin{array}{ll}\mathrm{Ba} / \mathrm{F} 3 \mathrm{MPL}^{\mathrm{W} 515 \mathrm{~L}} \quad 0.060 & 0.032\end{array}$

SET-2 JAK2 $2^{\mathrm{V} 17 \mathrm{~F}} \quad 0.032$

MB-02 JAK2 ${ }^{\mathrm{V}}$ 17F $\quad 0.022$

UKE-1 JAK2 V617F

MV4;11 FLT-3 ITD

CMK JAK3 ${ }^{A 572 V}$

K562 BCR-ABL
0.028

0.047

0.391

1.363
F
D

G
BVB808

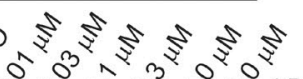

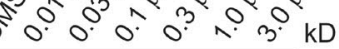

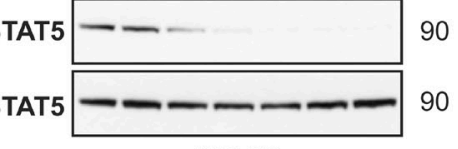

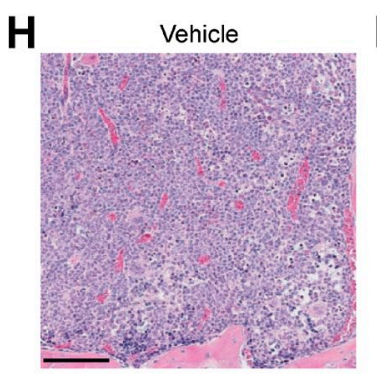

BVB808

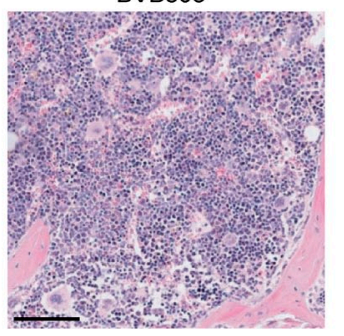

Baseline 3-day treatment 50-day treatment
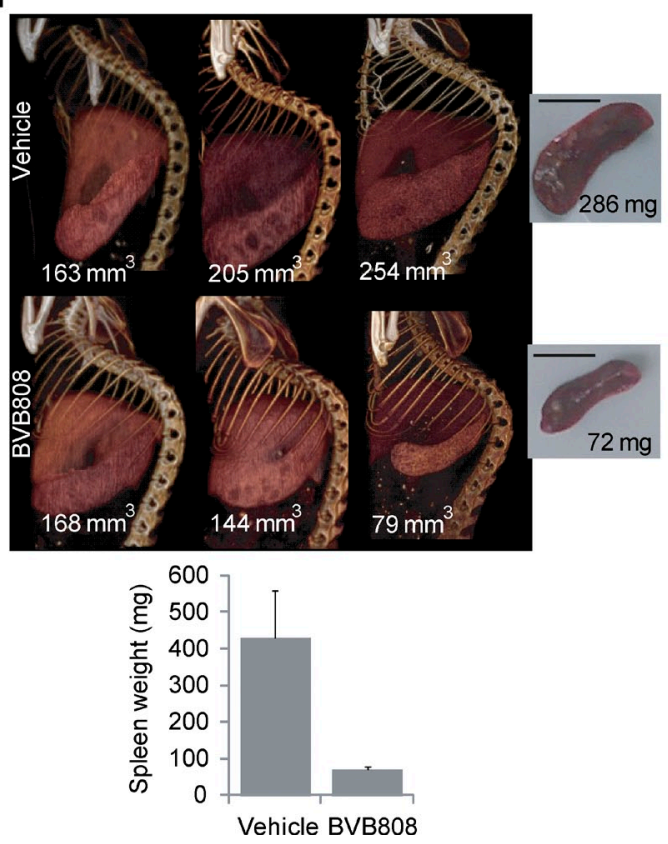
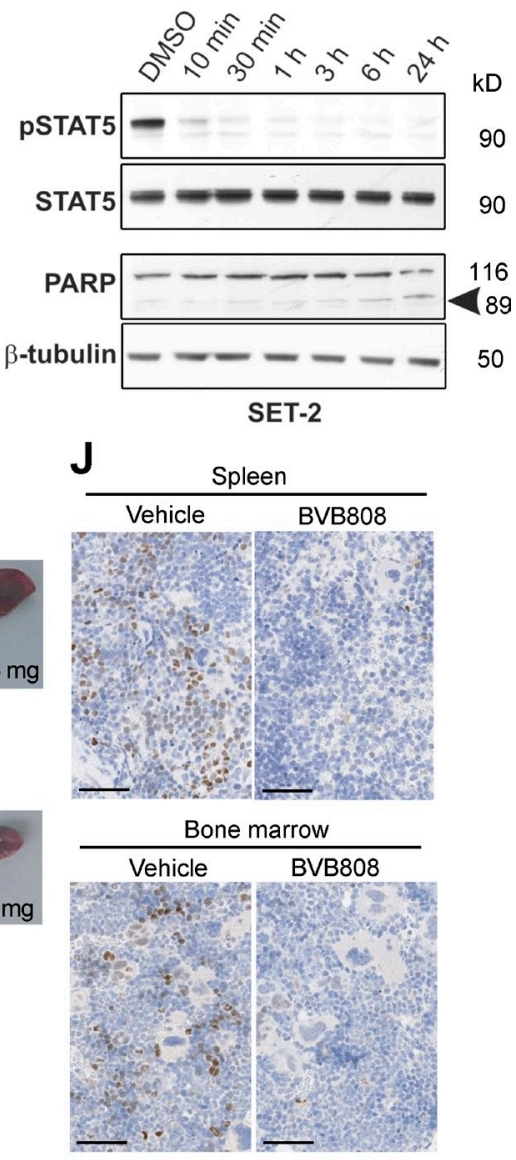

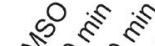

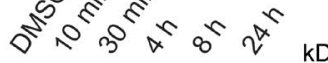
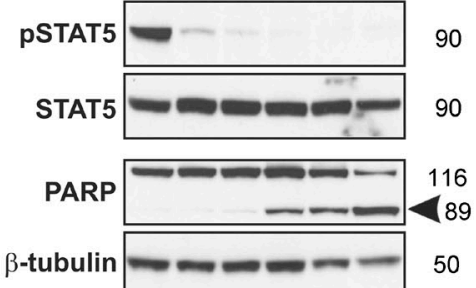

MB-02

Figure 1. JAK2 signaling as a therapeutic target. (A) Chemical structure of BVB808. (B) Kinase assays were performed with recombinant kinase (JH1) domains of the respective JAKs to determine the relative JAK-family selectivity of BVB808. (C) BVB808 activity against JAK2-dependent and JAK2-independent cell lines. $\mathrm{GI}_{50}$ values represent means of at least two independent experiments $(n=2-4)$. (D) JAK2 V617F mutant MB-02 cells were treated with increasing concentrations of BVB808 for 30 min. Inhibition of constitutive pSTAT5 was analyzed by Western blotting using a Tyr694 phospho-specific antibody. Total STAT5 is included as a loading control. (E) JAK2 V617F mutant SET-2 and JAK3 A572V mutant CMK cells were treated with increasing concentrations of BVB808 for $1 \mathrm{~h}$, and then extracted for immunoblotting. (F and G) MB-02 and SET-2 cells were treated with $1 \mu \mathrm{M}$ BVB808 for up to $24 \mathrm{~h}$. Cell extracts were prepared at different time points as indicated and probed for pSTAT5. Activation of cell death was assessed by detection of cleaved PARP (arrowhead). $\beta$-Tubulin was used as a loading control. (H) Efficacy of BVB808 was evaluated in a mouse bone marrow transplant model of Jak2 V617F-driven MPN after 3 wk of dosing. Bar, $100 \mu \mathrm{m}$. (I) In a separate experiment, CT imaging of mice before treatment and after 3 and $50 \mathrm{~d}$ of vehicle or BVB808. After imaging on day 50, the mice were sacrificed and the spleens were dissected and weighed. Spleen weight is shown on the right. Bar, $1 \mathrm{~cm}$. (J) Immunohistochemistry for pStat5 in spleen and bone marrow sections from samples collected $2 \mathrm{~h}$ after the last dose of vehicle or BVB808. Bar, $50 \mu \mathrm{m}$. 
A

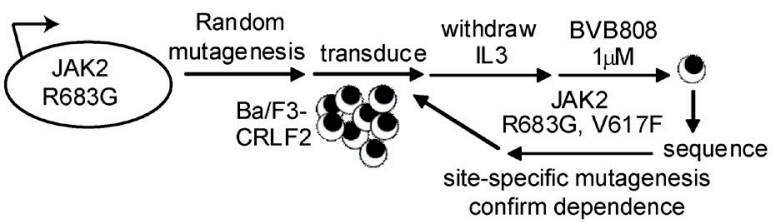

$B \quad-\mathrm{None} \neq \mathrm{G}=\mathrm{Y} 931 \mathrm{C}$

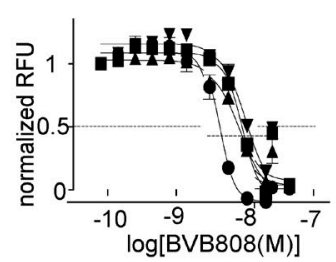

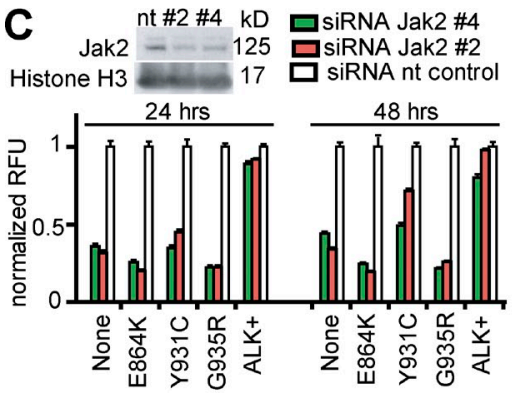

E

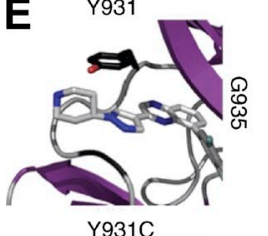

Y931C

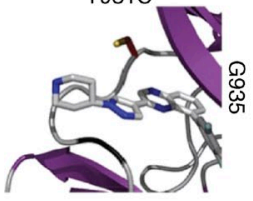

Y931
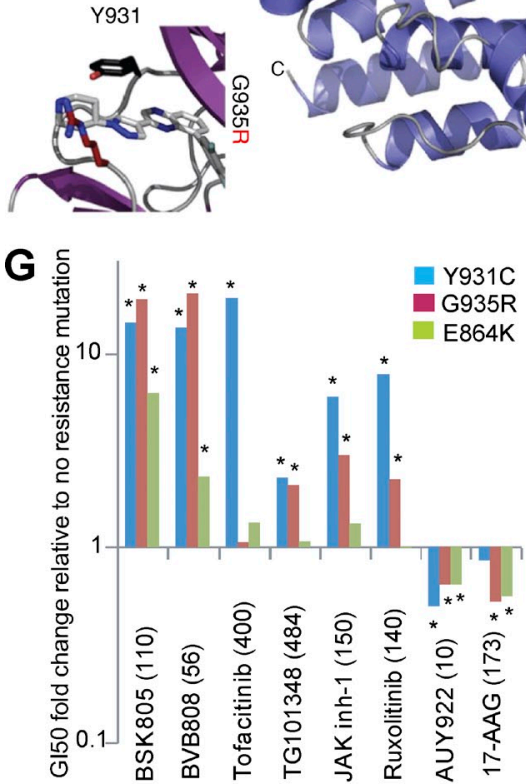

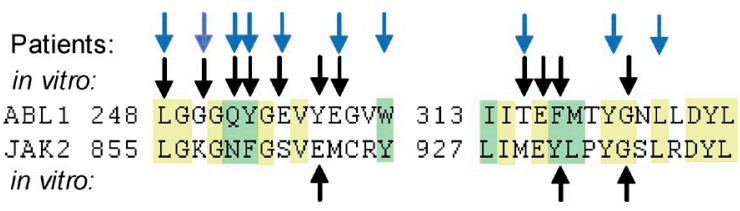

in vitro: $\quad \uparrow$

Figure 2. JAK2 alleles that confer resistance to enzymatic inhibitors. (A) In vitro mutagenesis screen of JAK2 R683G in Ba/F3-CRLF2 cells to identify mutations that confer resistance to BVB808. (B) Sensitivity to BVB808 was reduced in Ba/F3-CRFL2/JAK2 R683G cells harboring Y931C (GI 50 , 303 nM), G935R (462 nM), or E864K (427 nM) compared with no resistance mutation (96.4 nM; $\mathrm{P}<0.05$ for all 3 mutants). Proliferation was measured based on relative fluorescence units (RFU). Error bars represent SD. (C) Ba/F3 cells expressing ATIC-ALK (ALK+), EpoR/Jak2 V617F alone (none), or EpoR/Jak2 V617F with one of the three kinase domain mutations were transfected with either of two siRNA (\#4 and \#2) targeting mouse Jak2. The cells were grown in the absence of IL-3, and proliferation was measured after 24 and $48 \mathrm{~h}$ and normalized to cells from the same background transfected with nontargeting (nt) control siRNA. Representative immunoblot of VF/Y931C cells $24 \mathrm{~h}$ after transfection is shown. (D) Alignment of homologous regions in JAK2 and ABL1. 
CRLF2 (Fig. 2 B). Second, we cloned all three mutations independently in cis with mouse Jak2 V617F and expressed them with the erythropoietin receptor (EpoR) in Ba/F3 cells. Concurrent expression of Jak2 V617F with EpoR confers IL-3 independence in Ba/F3 cells (Levine et al., 2005). As expected, cells expressing EpoR with Jak2 V617F alleles harboring E864K, Y931C, or G935R also conferred IL-3 independence and resulted in multiagent resistance to JAK2 enzymatic inhibitors, similar to that noted for Ba/F3-CRLF2 cells harboring the resistance alleles in cis with JAK2 R683G (Table S1). Thus, all three alleles maintain their ability to confer resistance whether present in human or mouse JAK2, whether expressed in cis with the R683G or V617F mutation, and whether signaling through CRLF2 or EpoR. Finally, all three lines, but not $\mathrm{Ba} / \mathrm{F} 3$ cells dependent on ALK, were killed by Jak2 siRNA knockdown, indicating dependence on Jak2 (Fig. 2 C).

Three previous works identified mutations that conferred resistance to one or more JAK inhibitors by screening $\mathrm{Ba} / \mathrm{F} 3$ cells with EpoR and mutagenized JAK2 V617F or TEL-JAK2 (Table S2). Of note, E864K, Y931C, and G935R are the only mutations identified by multiple groups (including ours) through unbiased screening, strongly suggesting that they are bona fide resistance mutations. In a separate screen of mutagenized TEL-JAK2 expressed in Ba/F3 cells, we recovered the Y931S mutation after selection in BVB808 (Table S2), providing further evidence that this residue is critical for enzymatic JAK inhibitor activity. In addition, alignment of homologous regions of the JAK2 kinase domain (JAK homology domain 1 [JH1]) with ABL1 demonstrated that E864K, Y931C, and G935R are located in regions homologous to imatinib resistance hotspots in ABL1 (Fig. 2 D; Azam et al., 2003; Soverini et al., 2011).

\section{Resistance mutations are located near the ATP-binding region of the JAK2 kinase domain}

We performed structural modeling to evaluate the possible consequences of the three JAK2 resistance mutations (Fig. $2 \mathrm{E}$ ). Codons Y931 and G935 are located in the hinge region of the kinase domain (Fig. 2 E). G935R introduces a large and positively charged side chain that could sterically hinder drug binding (Fig. 2 E). Y931 is located in the adeninebinding region of the hinge and can interact directly with ATP-competitive inhibitors (Lucet et al., 2006). Y931C replaces a tyrosine, which is predicted to reduce inhibitor binding affinity. Introduction of a cysteine at this site also creates the potential for a targeted covalent inhibitor specific for this mutation, as previously demonstrated (Zhou et al., 2010). E864K is located in the middle of $\beta 3$ after the P-loop in the N-lobe (Fig. 2 E) and may modify the structure and flexibility of the preceding P-loop, thus destabilizing the conformation required for inhibitor binding.

\section{Mutations in the JAK2 kinase domain confer resistance across a panel of JAK inhibitors}

To determine whether the mutations confer resistance in the context of Jak2 V617F, we expressed Jak2 V617F alleles harboring Y931C, G935R, or E864K in Ba/F3 cells expressing EpoR. For these experiments, we used a panel of JAK enzymatic inhibitors (Fig. $2 \mathrm{~F}$ ) that included tool compounds (JAK inhibitor-1 [JAKinh-1] and NVP-BSK805 [BSK805; Baffert et al., 2010]) and agents in late-stage clinical trials (TG101348 [Pardanani et al., 2011; Wernig et al., 2008], tofacitinib [formerly tasocitinib; Manshouri et al., 2008], and ruxolitinib [formerly INCB18424; Pardanani, 2008]).

Y931C conferred a 2 to $>10$-fold resistance to all the JAK inhibitors (Fig. 2, G and H; and Table S1). G935R conferred resistance to all JAK inhibitors except for tofacitinib. E864K only conferred resistance to BVB808 and BSK805 (Fig. 2, $\mathrm{G}$ and $\mathrm{H}$; and Table S1).

\section{HSP90 inhibitors target JAK2 and overcome resistance to enzymatic kinase inhibitors}

JAK2 is a known client of HSP90 (Marubayashi et al., 2010). Inhibition of HSP90 promotes the degradation of both wildtype and mutant JAK2 (Bareng et al., 2007; Wang et al., 2009; Proia et al., 2011), and can improve survival in murine models of Jak2-dependent MPNs (Marubayashi et al., 2010). We hypothesized that resistance mutations within the JAK2 kinase domain would not affect JAK2 degradation induced by HSP90 inhibitors. We assayed the cytotoxicity of the resorcinylic isoxazole amide AUY922 (Fig. 2 F; Eccles et al., 2008) and the benzoquinone ansamycin 17-AAG in Ba/F3-EpoR cells that express Jak2 V617F (and Ba/F3-CRLF2 cells that express JAK2 R683G) with or without E864K, Y931C, or G935R. E864K, Y931C, and G935R did not confer resistance to either compound (Fig. 2, G and H; and Table S1). In fact, AUY922 was more potent against cells harboring Y931C (GI50, $4.92 \mathrm{nM})$, G935R (GI50, $6.44 \mathrm{nM}$ ), or E864K (GI50, $6.38 \mathrm{nM}$ ) compared with cells with no second site mutation (GI50, $10.00 \mathrm{nM}$; $\mathrm{P}<0.05$; Fig. 2, G and H; and Table S1).

\section{JAK2 G935R blocks binding of some but not all inhibitors}

We previously solved the co-crystal structure of the JAK2 JH1 domain in complex with BSK805 (Baffert et al., 2010). Using this structure, modeling of G935R indicated that an

Blue arrows indicate mutated codons in BCR/ABL1 reported to confer imatinib resistance in patients (Soverini et al., 2011). Black arrows indicate codons identified by in vitro mutagenesis of BCR/ABL1 (Azam et al., 2003) and JAK2 E864K, Y931C, and G935R mutations (below). (E) Structure of the kinase domain of JAK2 indicating E864, Y931, and G935 (right), with modeling of wild type, Y931C, and G935R (left, top to bottom). (F) Chemical structures of JAK inhibitors and the HSP90 inhibitor AUY922. (G) E864K, Y931C, and G935R were introduced into Jak2 V617F and expressed in Ba/F3-EpoR cells. Proliferation was assayed $48 \mathrm{~h}$ after exposure to indicated drug or vehicle in triplicate on two occasions based on RFU. ${ }^{*}, \mathrm{P}<0.05$ compared with no resistance mutation for that drug $\left(\mathrm{GI}_{50}\right.$ in nanomolar in parentheses). (H) Dose response curves based on RFU after $48 \mathrm{~h}$ of treatment with indicated drugs. Each data point was obtained in quadruplicate, and the experiment was independently repeated three times. Error bars indicate SD. 
arginine side chain would occlude the hydrophobic channel of the ATP-binding pocket. As a consequence, this mutation would decrease the binding affinity of compounds occupying the hydrophobic channel like JAKinh-1 or BSK805, but not affect the potency of tofacitinib, which does not bind in this region. Mutation of G935 to arginine, histidine, or glutamine reduced the inhibitory effects of JAKinh-1, but not tofacitinib, on JAK2 kinase domain activity (Fig. 3 A and Fig. S1 A). None of the codon 935 mutations had significant effects on $\mathrm{K}_{\mathrm{m}}$ or $\mathrm{V}_{\max }$ in vitro (Fig. S1 A).

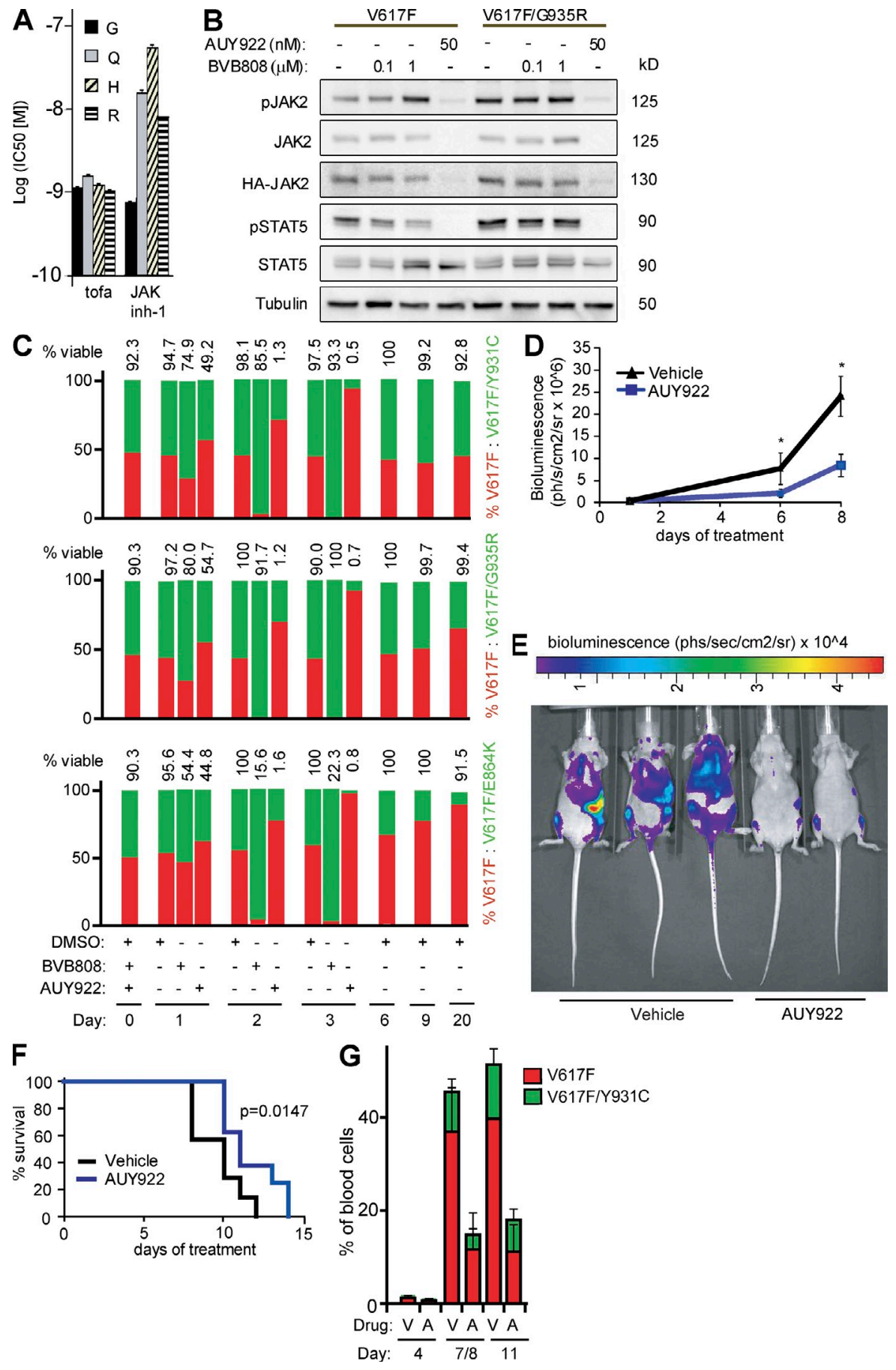

BVB808 treatment partially reduced activation state-specific phosphorylation of Stat5 in Ba/F3-EpoR/Jak2 V617F (VF) cells, but not in VF/G935R (Fig. 3 B) or VF/G935H cells (Fig. S1 B). BVB808 resulted in a paradoxical increase in Jak2 phosphorylation at Y1007/Y1008 within the Jak2 activation loop in VF but not in VF/G935R cells (Fig. 3 B), a phenomenon previously reported upon treatment of JAK2-dependent cells with other JAK2 enzymatic inhibitors (Grandage et al., 2006; Haan et al., 2009; Hart et al., 2011). Treatment of both lines with AUY922 at levels achievable in vivo (Eccles et al., 2008) reduced pJak2, pStat5, and total Jak2 (Fig. 3 B). Thus, HSP90 inhibitors maintain activity in Jak2-dependent cells with genetic resistance to enzymatic inhibitors.

\section{AUY922 is effective in vivo against cells dependent on resistant JAK2}

To determine whether the resistance mutations compromise JAK2-dependent proliferation, we performed a competitive growth assay between VF cells and cells harboring Jak2 V617F with Y931C, G935R, or E864K in 1:1 mixtures (Fig. 3 C). Over a $20-$ d growth

Figure 3. Functional characterization of resistance mutations in JAK2 V617F. (A) $I C_{50}$ values of tofacitinib or JAKinh-1 determined using purified wild-type, G9350, G935H, or G935R JAK2 kinase domains. (B) Ba/F3-EpoR/HA-Jak2 V617F or Ba/F3-EpoR/ HA-Jak2 V617F/G935R cells were treated with the indicated drugs for $16 \mathrm{~h}$, and lysates were immunoblotted with antibodies against hemagglutinin (HA) or the indicated proteins. (C) Ba/F3-EpoR cells expressing Jak2 V617FThy1.1 and Ba/F3-EpoR cells expressing Jak2 V617F/Y931C-GFP (top)/G935R-GFP (middle)/ or E864K-GFP (bottom) were mixed 1:1. The relative fraction of each cell population was quantified by flow cytometry in the presence or absence of drug, as indicated. (D) Mice injected with 1:1 mixes of luciferized Ba/F3-EpoR-JAK2 V617F-Thy1.1 and luciferized Ba/F3-EpoR-Jak2 V617/Y931C-GFP cells were treated with AUY922 $(n=8)$ or vehicle $(n=9)$ and luciferase was measured at indicated time points. Error bars indicate standard error of the mean. ${ }^{*}, \mathrm{P}<0.05$ compared with vehicle. (E) Representative luciferase imaging of AUY922- and vehicle-treated mice on day 8 of treatment. (F) Survival of mice treated with vehicle or AUY922. (G) Peripheral blood was analyzed from mice treated with vehicle $(V)$ or AUY922 (A) by flow cytometry for percentage of mononuclear cells expressing GFP (Jak2 V617F/Y931C) or Thy1.1 (Jak2 V617F). 4 mice were analyzed at each time point except for vehicle day $11(n=2)$. Error bars indicate SEM. 
period, cells harboring Jak2 V617F/Y931C had no competitive growth disadvantage, whereas cells harboring Jak2 V617F/G935R or JAK2 V617F/E864K were outcompeted by VF cells (Fig. $3 \mathrm{C}$ ).

Treatment of the 1:1 mixtures with BVB808 led to a rapid predominance of cells harboring the resistance mutation over VF cells (Fig. 3 C). Treatment of all three mixtures with AUY922 resulted in $<2 \%$ viability within $48 \mathrm{~h}$. Strikingly, cells harboring Jak2 V617F alone predominated among surviving cells, consistent with the increased potency of AUY922 against cells harboring the resistance mutations (Fig. 2, G and $\mathrm{H}$; and Table S1).

To determine whether AUY922 is effective in vivo against cells harboring Jak2 enzymatic inhibitor resistance, we transplanted nude mice with a 1:1 mix of luciferized $\mathrm{Ba} / \mathrm{F} 3$ cells expressing (a) EpoR/Jak2 V617F/Y931C with GFP, and (b) EpoR/Jak2 V617F alone with Thy1.1. We elected to transplant a 1:1 mix to allow for monitoring of the effects of AUY922 on both Jak2 V617F- and Jak2 V617F/Y931C-dependent cells. Once luciferase activity was measurable in the mice (day 4 after injection), we treated them with $50 \mathrm{mg} / \mathrm{kg}$ of either
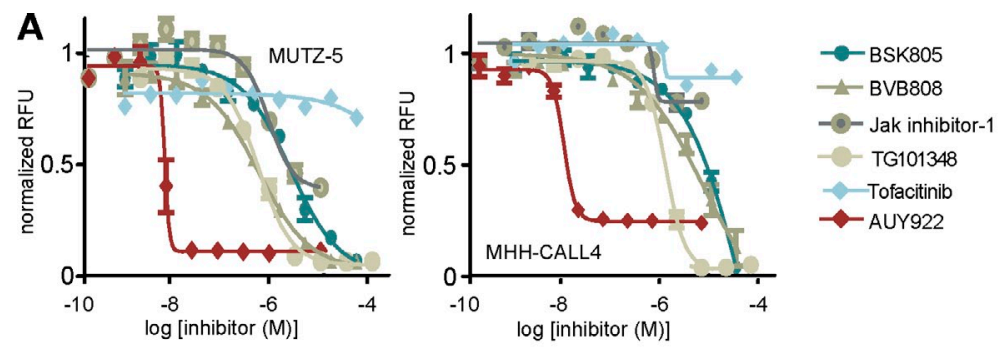

B

\begin{tabular}{|c|c|c|c|c|c|c|c|}
\hline & BSK805 & BVB808 & TG101348 & Ruxolitinib & JAK inh-1 & Tofacitinib & AUY922 \\
\hline MHH-CALL4 & 6.352 & 7.525 & 1.335 & $>30$ & 20.851 & $>30$ & 0.026 \\
\hline MUTZ-5 & 4.943 & 1.596 & 1.729 & 15.423 & 2.675 & $>30$ & 0.025 \\
\hline K562 & 8.930 & 3.381 & 3.106 & $>30$ & 1.289 & $>30$ & 0.109 \\
\hline CRLF2/JAK2 RG & 0.145 & 0.028 & 0.376 & 0.039 & 0.102 & 0.244 & 0.001 \\
\hline CRLF2/IL7R+TSLP & 0.354 & 0.221 & 0.265 & 0.043 & 0.128 & 0.634 & 0.003 \\
\hline EPOR+EPO & 0.307 & 0.134 & 0.674 & 0.129 & 0.272 & 0.736 & 0.009 \\
\hline EPOR/JAK2 V617F & 0.121 & 0.042 & 0.244 & 0.102 & 0.126 & 0.404 & 0.011 \\
\hline CRLF2 F232C & 0.156 & 0.052 & 0.251 & 0.052 & 0.083 & 0.178 & 0.002 \\
\hline $\mathrm{BCR} / \mathrm{ABL}$ & 1.228 & 0.324 & 0.958 & $>30$ & 1.29 & $>30$ & 0.002 \\
\hline
\end{tabular}

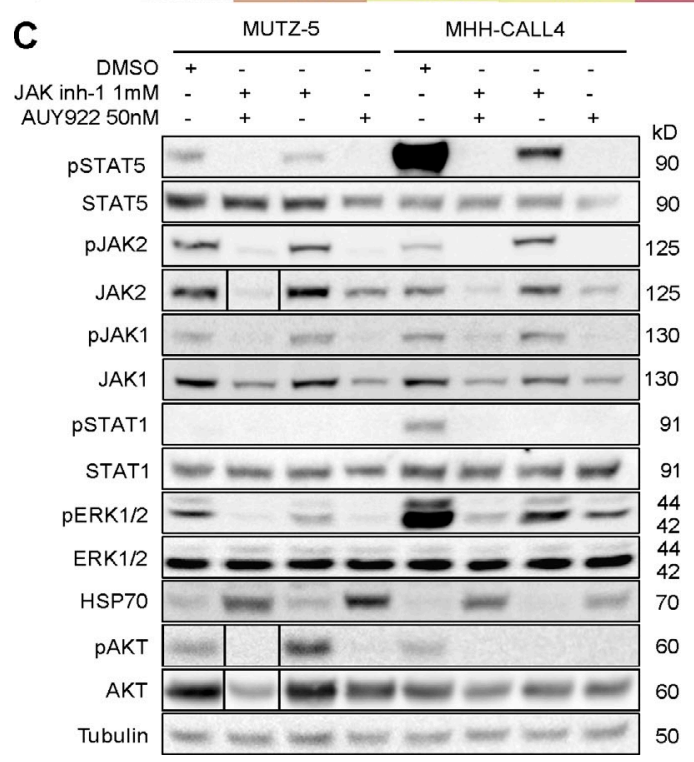

vehicle or AUY922 thrice weekly i.v.. The dose of AUY922 was selected based on previous activity in preclinical breast cancer models (Jensen et al., 2008). In addition, we demonstrated that this dose of AUY922 reduces spleen size and hematocrit in the Jak2 V617F bone marrow transplant model of MPN.

AUY922 reduced bioluminescence compared with vehicle (Fig. 3, D and E), which was associated with an improvement in overall survival for AUY922-treated mice (Fig. $3 \mathrm{~F}$; P = 0.0147). To clarify whether the activity of AUY 922 was affected by the Y931C mutation, we performed flow cytometry on peripheral blood after 4, 7, and $11 \mathrm{~d}$ of treatment. AUY922 treatment did not increase the relative ratio of cells expressing JAK2 V617F/Y931C compared with cells expressing JAK2 V617F alone, consistent with similar activity independent of the resistance mutation (Fig. $3 \mathrm{G}$ ).

\section{HSP90 inhibitors have potent activity in CRLF2-rearranged B-ALL cells}

Outcomes among patients with CRLF2-rearranged B-ALL are poor, with $<20 \%$ relapse-free survival among adults (Yoda et al., 2010) and $\sim 40 \%$ among children (Harvey et al., 2010). To explore the utility of HSP90 inhibition in CRLF2rearranged B-ALL, we exposed the MHH-CALL4 and MUTZ-5 cell lines, which both have CRLF2/IGH rearrangements to AUY922. MHHCALL4 cells also harbor a JAK2 I682F mutation, whereas MUTZ-5 cells have a JAK2 R683G mutation. Both MUTZ-5 and MHH-CALL4 were highly sensitive to AUY922 ( $\mathrm{GI}_{50}$, 25-26 nM), with 50 to $>1,000$-fold

Figure 4. JAK2 and HSP90 inhibition in CRLF2-rearranged B-ALL cell lines.

(A) MHH-CALL4 and MUTZ-5 cells were exposed to JAK2 enzymatic inhibitors and the HSP90 inhibitor AUY922 at indicated concentrations for $96 \mathrm{~h}$, and proliferation was quantified based on RFU. Error bars represent SD.

Shown results are representative of two independent experiments performed in quadruplicate. (B) $\mathrm{GI}_{50}$ concentrations for JAK2 and HSP9O inhibitors after $2 \mathrm{~d}$ (Ba/F3 cell lines) or $3 \mathrm{~d}$ (MHH-CALL4 and MUTZ- 5 cell lines) of exposure. K562 cells harbor BCR/ABL1 and not CRLF2 rearrangements. (C) Immunoblotting in MHH-CALL4 and MUTZ- 5 cells exposed to $1 \mu \mathrm{M}$ JAKinh-1, 50 nM AUY922, combination, or vehicle for $16 \mathrm{~h}$. (D) MHH-CALL4 cells were transfected with siRNA against the indicated JAK family member or with scrambled control, and lysates were collected for immunoblotting after $72 \mathrm{~h}$. (E) Immunoblotting of Ba/F3-CRLF2/ JAK2 R683G cells for the indicated total or phosphorylated proteins after treatment with the indicated doses of HSP990 or PU-H71. 
superior potency compared with the panel of JAK2 enzymatic inhibitors (Fig. 4, A and B). AUY922 was also highly active against a panel of $\mathrm{Ba} / \mathrm{F} 3$ lines dependent on CRLF2 and JAK2 $\left(\mathrm{GI}_{50}, 1-11\right.$ nM; Fig. $\left.4 \mathrm{~B}\right)$.

MHH-CALL4 and MUTZ-5 cells have constitutive phosphorylation of STAT5 (Y694), JAK2 (Y1007/1008), JAK1 (Y1022/1023), ERK1/2 (T202/Y204), and AKT (S473; Fig. 4 C), which is indicative of activation of these pathways. Using RNAi to individually deplete the JAK family members, we confirmed that STAT5 phosphorylation in MHHCALL4 cells is dependent on JAK2 (Fig. 4 D). Treatment with JAKinh-1 for $16 \mathrm{~h}$ reduced, but did not eliminate pSTAT5 and pERK1/2 in both lines. JAKinh-1 had little effect on pJAK1 and promoted increases in pAKT in MUTZ-5 and pJAK2 in MHH-CALL4 (Fig. 4 C), as observed in Ba/F3-JAK2 V617F cells treated with BVB808 (Fig. 3 B).

Treatment with AUY922 for $16 \mathrm{~h}$ more extensively reduced or eliminated phosphorylation of all the targets. Total JAK2, and to a lesser extent JAK1, were also reduced in AUY922-treated cells (Fig. 4 C). AUY922 promoted HSP70 up-regulation in both lines (Fig. 4 B), a known heat shock factor 1 (HSF1)-mediated pharmacodynamic response to HSP90 inhibition. Similar effects on pJAK2, pStat5, pErk1/2, and pAkt were observed in Ba/F3-CRLF2/JAK2 R683S cells treated with the HSP90 inhibitors HSP990 (GI50, $14.9 \mathrm{nM}$; unpublished data) or PU-H71 (GI50, $85.7 \mathrm{nM}$; Cerchietti et al., 2009; Fig. 4 E). Only MHH-CALL4 has constitutive phosphorylation of STAT1, and this was eliminated by treatment with either JAKinh-1 or AUY922.

The combination of AUY922+JAKinh-1 had little or no additional effect on target phosphorylation compared with AUY922 alone (Fig. 4 C). In addition, pairwise dose-response studies with isobologram analysis failed to identify synergistic effects from combination treatment with AUY922+BVB808 in MHH-CALL4 or MUTZ-5 cells (unpublished data).

\section{HSP90 inhibition elicits a transcriptional signature enriched for JAK2 and HSF1 signaling}

To compare the downstream programs resulting from JAK2 and HSP90 inhibition, we performed transcriptional profiling on MUTZ-5 and MHH-CALL4 cells treated with vehicle (DMSO), JAKinh-1, AUY922, or JAKinh-1+AUY922 (combo). Unsupervised hierarchical clustering distinguished samples treated with AUY922 (or combination) from those treated with JAKinh-1 or vehicle (Fig. 5 A). We generated a heat map of the top/bottom differentially expressed genes for each condition (false discovery rate $(\mathrm{FDR})<0.25$ and fold change $(\mathrm{FC})>2.5$; Table S3), which indicated that AUY922 treatment modulated the same genes targeted by JAKinh-1 (Fig. 5 B), but to a larger extent. GSEA also demonstrated that STAT5A signatures were enriched upon treatment with JAKinh-1, AUY922, or JAKinh-1+AUY922 (Fig. 5 C). To formally demonstrate that AUY922 targets the same genes as JAKinh-1, we defined a "JAK inhibitor signature" from the top/bottom 250 most differentially expressed genes after treatment with JAKinh-1. Using gene set enrichment analysis (GSEA), the JAK inhibitor signature was highly enriched upon treatment with AUY922 (FDR q-value $=0.003$; Fig. 5 D).

HSP90 acts at the posttranscriptional level, thus immediate targets (i.e., HSP90 clients) are not directly assessed by
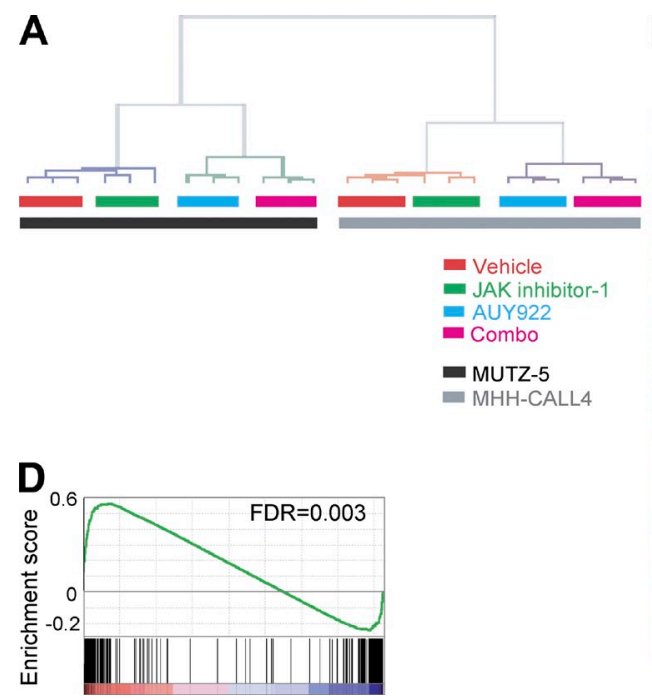
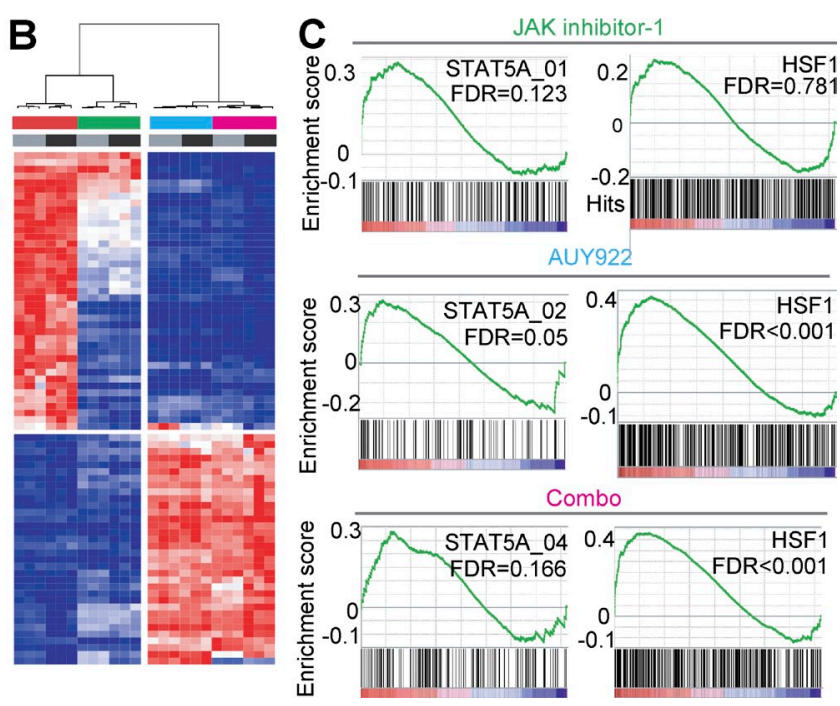

Figure 5. Transcriptional profiling of JAK2 and HSP90 inhibition in CRLF2-rearranged B-ALL cell lines. MHH-CALL4 and MUTZ-5 cells were treated in triplicate for $14 \mathrm{~h}$ with either $1 \mu \mathrm{M}$ JAKinh-1, $50 \mathrm{nM}$ AUY922, the combination of both (combo), or vehicle. (A) Unsupervised hierarchical clustering of transcriptional profiles. (B) Hierarchical clustering and heat map of the most differentially expressed genes within the top/bottom 20 (FDR $<0.25$ and FC $>2.5$ ) between a treatment group and vehicle for MUTZ-5 and MHH-CALL4 cells. More abundant genes are visualized on the colorimetric scale in red, less abundant genes in blue. (C) GSEA was performed for each treatment condition with STAT5A and HSF1 gene signatures. (D) A JAK inhibitor signature was determined from the top/bottom 250 most differentially expressed genes after treatment with JAKinh-1. This signature was used to perform GSEA for comparison AUY922 versus vehicle treatment. 
transcriptional profiling. We used the C3 database from the MsigDB compendium to perform a transcription factorbinding site enrichment analysis of the most differentially expressed genes between JAKinh-1 and AUY922. The top five ranked transcription factor-binding sites enriched in the AUY922-treated group were all heat-shock factors (HSF; FDR $<0.05)$, which are known to be transcriptionally responsive to HSP90 inhibition (Neckers, 2007). GSEA revealed that an HSF1 signature was only enriched upon treatment with AUY922 or AUY922+JAKinh-1, but not with JAKinh-1 alone (Fig. 5 C).

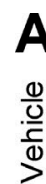
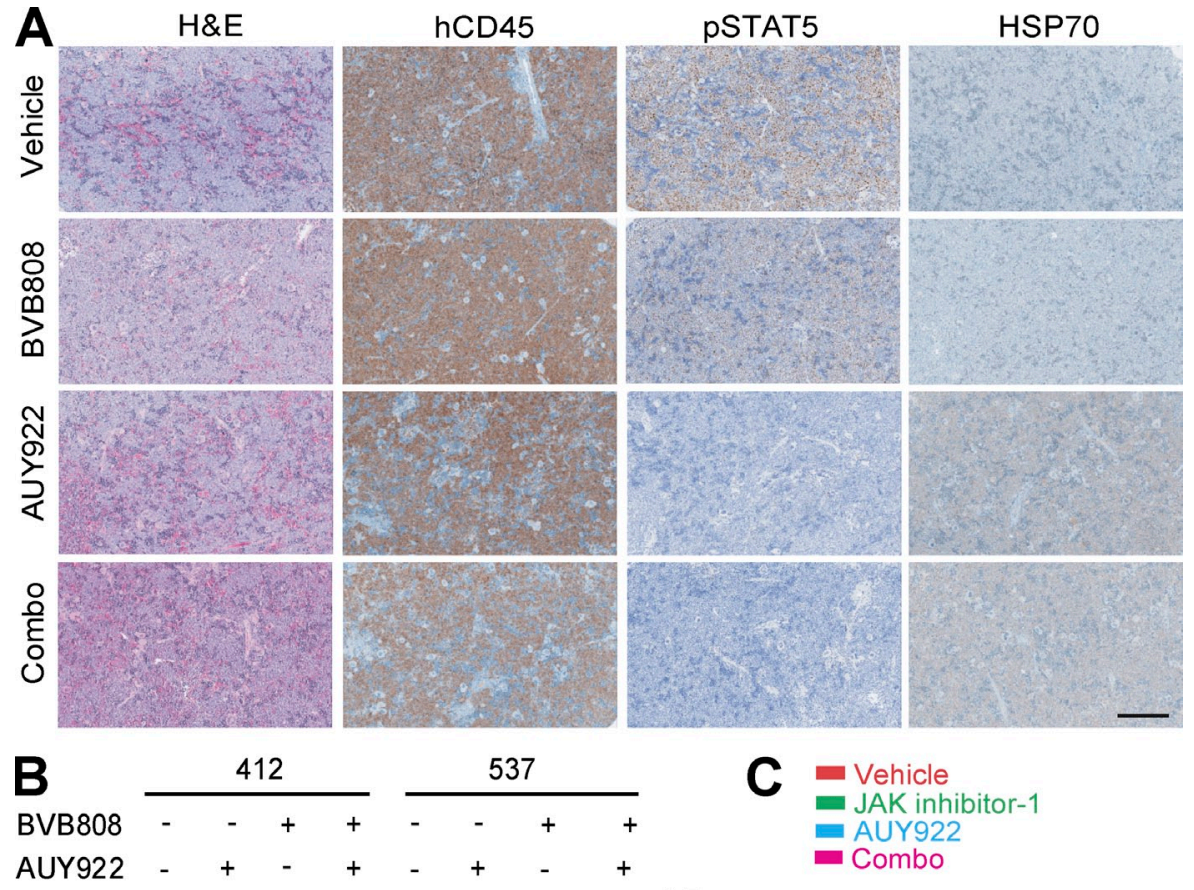

C Vehicle - JAK inhibitor-1 - AUY922

AUY922 - + - + - + - +

\begin{tabular}{|c|c|c|c|c|c|c|c|}
\hline Vehicle & + & - & - & - & + & - & - \\
\hline pSTA & $\infty$ & & 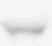 & & س & & 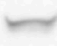 \\
\hline
\end{tabular}
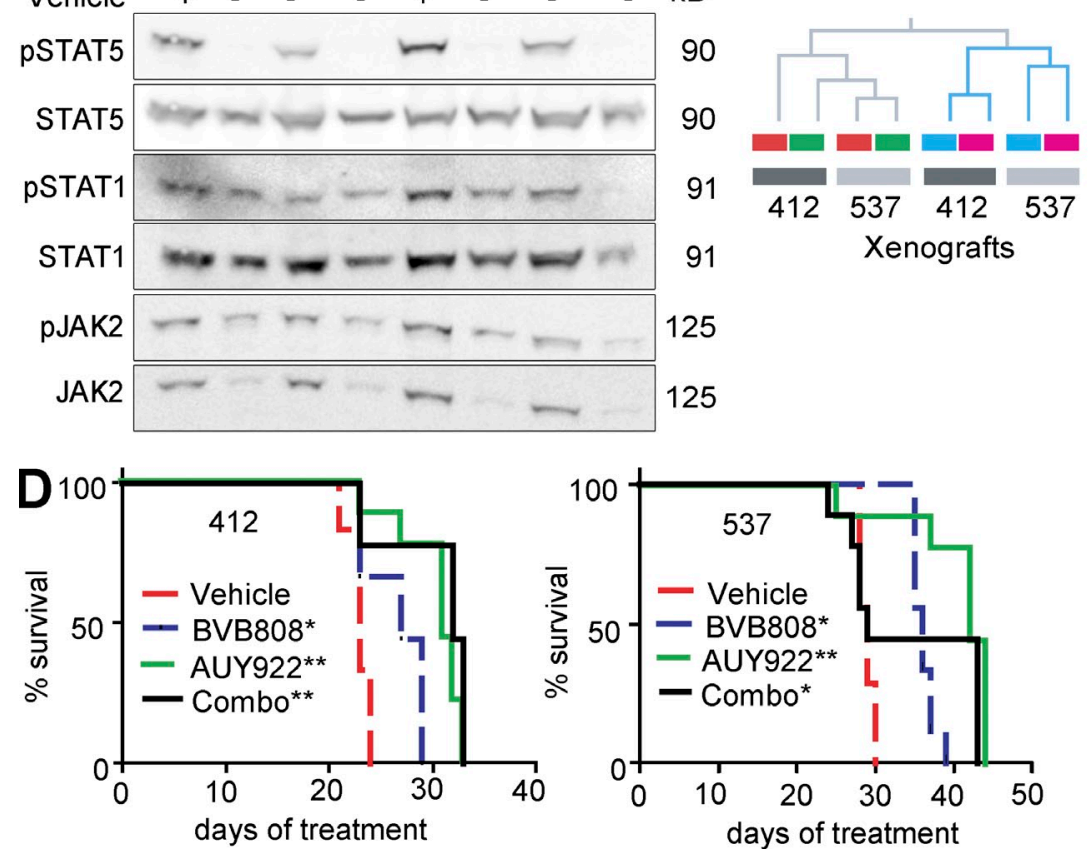

HSP90 inhibition is effective against human CRLF2-rearranged B-ALL in vivo

To extend our findings to the in vivo treatment of human B-ALL, we established primary B-ALL xenografts from CRLF2-rearranged, patient-derived bone marrow samples ( $n=40$ for each sample) in NOD.Cg-Prkdc ${ }^{\text {scid }} \mathrm{Il}_{2} \mathrm{rg}^{\mathrm{tm} 1 \mathrm{Wjl}} / \mathrm{SzJ}$ (NSG) mice. Patient sample 412 harbors a CRLF2/IGH translocation and a JAK2 R683S mutation. Patient sample 537 harbors a $P 2 R Y 8-C R L F 2$ rearrangement and lacks a somatic mutation within the known components of CRLF2 signaling, based on transcriptome and exome sequencing (unpublished data). To stringently assay established disease in vivo, we sacrificed sentinel animals weekly after transplantation to assess engraftment. Once bone marrow leukemia burden exceeded 30\% (based on flow cytometry of sentinel mice for human CD45), we initiated treatment with $50 \mathrm{mg} / \mathrm{kg}$ BVB808 twice daily by oral gavage, $50 \mathrm{mg} / \mathrm{kg}$ AUY922 thrice weekly i.v., BVB808+AUY922, or vehicle. The dose of BVB808 was selected based on the demonstrated activity at this dose in Jak2 V617F-driven MPNs (Fig. 1, H-J) and previous studies that demonstrated weight loss at higher doses (not depicted).

After $5 \mathrm{~d}$ of treatment, we sacrificed animals to assess pharmacodynamic

Figure 6. JAK2 and HSP90 inhibition in CRLF2-rearranged human xenografts. NSG mice were injected with primary 412 or 537 cells i.v. ( $n=40$ per line). When leukemia engraftment was $>30 \%$ in the bone marrow, mice were divided into 4 treatment groups: $50 \mathrm{mg} / \mathrm{kg}$ AUY922 i.v. thrice weekly, $50 \mathrm{mg} / \mathrm{kg}$ BVB808 by oral gavage twice daily, combination, or vehicle. (A) Immunohistochemistry using H\&E or antibodies against human CD45 (hCD45), pSTAT5, or HSP70 in spleens obtained from NSG mice engrafted with 412 leukemias. Mice were treated for $5 d$, and spleens were harvested 2-4 $\mathrm{h}$ after the last dose. (B) Immunoblotting of lysates from spleens obtained from NSG mice engrafted with 412 or 537 leukemias and then treated for $5 \mathrm{~d}$ with the indicated agent(s). (C) Unsupervised hierarchical clustering of transcriptional profiles of 412 or 537 leukemias engrafted in NSG mice after treatment with BVB808, AUY922, BVB808+AUY922 (combination), or vehicle. (D) Survival among NSG mice engrafted with primary human CRLF2-rearranged B-ALL samples and treated with BVB808, AUY922, combination, or vehicle. ${ }^{*}, \mathrm{P}<0.05$ compared with vehicle; ${ }^{*}, \mathrm{P}<0.05$ compared with BVB808. 
endpoints. Spleens from mice treated with vehicle or BVB808 had nearly complete effacement by B-ALL, whereas AUY 922 or BVB808+AUY922 treatment resulted in visible islands of hematopoiesis (Figs. 6 A). Based on immunohistochemistry, mice receiving AUY922 or BVB808+AUY922 (combo), but not BVB808 or vehicle, had nearly complete loss of pSTAT5 and up-regulation of HSP70 (Fig. 6 A). Immunoblotting of spleens from treated mice demonstrated similar findings to those observed after treatment of MUTZ5 and MHHCALL4 (Fig. 4 B); specifically, reductions in pSTAT5, pJAK2, and total JAK2 in AUY922- or BVB808+AUY922treated mice (Fig. 6 B). In contrast, treatment with singleagent BVB808 only modestly suppressed pSTAT5 (Fig. 6 B). As noted in MHH-CALL4 cells, treatment with either BVB808 or AUY922 reduced pSTAT1 (Fig. 6 B).

We performed transcriptional profiling on bone marrow from mice after $5 \mathrm{~d}$ of treatment. Unsupervised hierarchical clustering (Fig. $6 \mathrm{C}$ ) demonstrated the same pattern of clustering observed after treatment of B-ALL cell lines (Fig. 5 A). Specifically, mice treated with AUY922 or BVB808+AUY922 clustered together, whereas vehicle- and BVB808-treated mice clustered together (Fig. $6 \mathrm{C}$ ), indicating the dominant impact of HSP90 inhibition.

Treatment with either BVB808 or AUY922 prolonged overall survival compared with vehicle (Fig. $6 \mathrm{D} ; \mathrm{P}=0.01$ for both xenografts). Treatment with AUY922 further prolonged overall survival compared with BVB808 ( $\mathrm{P}<0.01$ for both xenografts), whereas the combination of BVB808 and AUY922 had no additional benefit compared with AUY922 alone (Fig. 6 D).

\section{DISCUSSION}

In this study, we describe point mutations near the ATPbinding region of the JAK2 kinase (JH1) domain that confer resistance to a broad panel of enzymatic JAK inhibitors. All three mutations are in regions homologous to imatinib resistance hotspots in ABL1 (Azam et al., 2003; Soverini et al., 2011) and promote multiagent resistance in the context of Jak2 V617F or JAK2 R683G.

Our screen recovered only three amino acid substitutions capable of supporting growth in the presence of BVB808 while maintaining JAK2 R683G function. In contrast, the previous mutagenesis screens with $B C R / A B L 1$ recovered 112 distinct amino acid substitutions affecting 90 residues (Azam et al., 2003). It is possible that we only recovered a small fraction of the mutations capable of conferring resistance to JAK inhibitors. If so, recovery might have been limited by screening with $1 \mu \mathrm{M}$ BVB808, which exceeded the $\mathrm{GI}_{50}$ of the parental cell line $(28 \mathrm{nM})$ by $>30$-fold. However, selection in lower doses resulted in escape clones that lacked JAK2 mutations (unpublished data). Selection in a relatively high dose of BVB808 may also explain why we did not identify mutations outside the kinase domain. These mutations were reported in imatinib-resistant BCR/ABL1, but are typically associated with only a modest increase in $\mathrm{GI}_{50}$ (Azam et al., 2003).
An alternative possibility is that genetic resistance to JAK enzymatic inhibitors is confined to only a few residues, as other mutations either confer only a small magnitude of resistance or compromise JAK2 function. Other groups have reported additional mutations that confer resistance (Table S2), although many of these mutations are outside the ATP-binding pocket or P-loop, raising questions about their effects. It will be important to stringently assay the dependence of cells expressing these alleles on JAK2 enzymatic activity, as we did for E864K, Y931C, and G935R. Notably, mutations in the kinase domain of BCR/ABL1 have altered kinase activity and transformation potency (Griswold et al., 2006). Both G935R and E864K promoted a competitive growth disadvantage in $\mathrm{Ba} / \mathrm{F} 3$ cells. This disadvantage was reversed by treatment with BVB808 but suggests that, akin to clones harboring imatinib-resistance mutations, clones harboring either of these mutations would be outcompeted in vivo by clones lacking a resistance mutation in patients who discontinue JAK inhibitor treatment.

The HSP90 ATPase is a molecular chaperone central to the conformational maturation of numerous client proteins, including a multitude of oncogenic factors involved in cancer cell growth and survival (Richardson et al., 2011). Recently, JAK2 has been shown to be an HSP90 client (Marubayashi et al., 2010), and HSP90 inhibitors are active in preclinical models of MPN in vitro and in vivo. We demonstrated that HSP90 inhibition overcomes genetic resistance within JAK2 to enzymatic inhibitors. In fact, we observed a lower $\mathrm{GI}_{50}$ value for AUY922 in VF cells harboring any of the three resistance mutations compared with cells lacking a resistance mutation (Fig. 2, G and $\mathrm{H}$; and Table S1), suggesting an increased requirement for HSP90 activity.

We also noted persistent JAK2 signaling upon treatment of B-ALL cells harboring CRLF2 rearrangements and JAK2 mutations with enzymatic JAK2 inhibitors. Similar increases in pJAK2 upon treatment of JAK2-dependent cells with enzymatic JAK inhibitors have been reported (Grandage et al., 2006; Haan et al., 2009; Hart et al., 2011). For MUTZ-5 and $\mathrm{MHH}-\mathrm{CALL} 4$ cells, $\mathrm{GI}_{50}$ concentrations with multiple JAK inhibitors were 20-40-fold higher than those observed for Jak2 V617F-dependent myeloid cell lines. In contrast, CRLF2rearranged B-ALL cell lines were highly sensitive to structurally divergent HSP90 inhibitors. HSP90 inhibition was associated with more potent disruption of JAK2 signaling in CRLF2rearranged B-ALL cells, as indicated by both posttranslational and transcriptional endpoints. It will be important to validate the transcriptional findings in additional datasets.

The greater suppression of JAK2 signaling upon treatment with HSP90 inhibitors correlated with prolonged survival of mice bearing primary human B-ALL xenografts. Thus, AUY922 had superior activity compared with the panel of JAK2 enzymatic inhibitors in CRLF2-rearranged $\mathrm{B}-\mathrm{ALL}$ in vitro and compared with BVB808 in vivo. It remains possible that an alternative JAK2 inhibitor would have more activity against JAK2-dependent B-ALL in vivo. However, the high GI50 values noted upon treatment of MHH-CALL4 
and MUTZ-5 with any of the JAK enzymatic inhibitors (Fig. 4 B) argues against this possibility.

The lack of synergy between JAK and HSP90 inhibitors combined with the enrichment of a JAK inhibitor signature upon treatment of MHH-CALL4 and MUTZ-5 with AUY922 (Fig. 5) suggests that AUY922 is primarily functioning through inhibition of JAK2 signaling. However, the HSP90 chaperone complex stabilizes a large number of client proteins, including multiple factors involved in signaling cascades that affect proliferation and survival (Neckers, 2007; Trepel et al., 2010). Not surprisingly, HSP90 inhibitors like AUY922 (Eccles et al., 2008) have broad activity against a variety of hematologic and epithelial cell lines. This raises the possibility that the cytotoxic effects of HSP90 inhibitors in JAK2-dependent cells involve additional pathways beyond JAK-STAT signaling. A prime candidate is AKT, which is known to be an HSP90 client and can be therapeutically targeted in a large fraction of B-ALL cases (Abramson et al., 2009; Levy et al., 2009; Sanda et al., 2010). However, AUY922 had minimal effects on total AKT in MUTZ-5 and MHH-CALL4 cells (Fig. 4). In addition, AUY922 at concentrations between 25-400 $\mathrm{nM}$ can reversibly inhibit the in vitro proliferation of bone marrow stromal cells (Stühmer et al., 2008), raising the possibility that some AUY922 effect could be leukemia cell-extrinsic.

In conclusion, we demonstrate that resistance to a panel of JAK enzymatic inhibitors, through either kinase domain mutation or incomplete inhibition of JAK2 signaling, can be overcome by inhibition of HSP90. These studies provide a proof-of-concept for the therapeutic targeting of HSP90 in JAK2-dependent cancers and establish the rationale for clinical evaluation of this concept.

\section{MATERIALS AND METHODS}

Reagents and cell lines. Jak Inhibitor I, a pan Jak inhibitor, was purchased from EMD. NVP-BSK805, BVB808, and AUY922 were provided by Novartis. TG101348 was synthesized by the Memorial Sloan-Kettering Cancer Center Organic Synthesis Core Facility. Tofacitinib was purchased from Selleck. 17-AAG was purchased from Selleck. PU-H71 6-amino-8-[(6-iodo-1,3-benzodioxol-5-yl)thio]-N-(1-methylethyl)-9H-purine9-propanamine hydrate was synthesized by the Chiosis Laboratory. Stock aliquots were prepared in DMSO, stored at $-20^{\circ} \mathrm{C}$, and diluted in appropriate media before use.

$\mathrm{Ba} / \mathrm{F} 3$ (American Type Culture Collection) cells were maintained in RPMI 1640 medium (Invitrogen) with 10\% FCS (Invitrogen) and 500 pg/ml IL-3 (Millipore) or $1 \mathrm{ng} / \mathrm{ml}$ TSLP (R\&D Systems). Ba/F3 were stably transduced with CRLF2 (MSCVpuro), IL7R (MSCV-GFP), EpoR (MSCV puro $_{\text {), }}$ $H A-J A K 2\left(\mathrm{MSCV}_{\text {neo }}\right)$, and Jak2 (MSCV-IRES-GFP) with or without activating mutations in the pseudokinase domain (R683G or V617F) as indicated.

The B-ALL cell lines MUTZ-5 (harbors IGH/CRLF2 and JAK2 R683G) and MHH-CALL4 (harbors IGH/CRLF2 and JAK2 I682F) cells were obtained from Deutsche Sammlung von Mikroorganismen und Zellkulturen (Braunschweig, Germany) and grown in RPMI 1640 with 20\% FBS.

Random mutagenesis screen of human JAK2 R683G. We modified a previously described approach (Azam et al., 2003) to generate a randomly mutagenized cDNA library of human JAK2 R683G. In brief, JAK2 R683G was cloned into the retroviral expression vector $\mathrm{pMSCV}_{\text {neo }}$ att, which was constructed by inserting Reading Frame Cassette A (Invitrogen) into the multicloning site of $\mathrm{pMSCV}_{\text {puro }}$ (Takara Bio Inc.) using the Gateway Vector Conversion System (Invitrogen), as previously described (Yoda et al., 2010).

In separate aliquots, we mutagenized a total of $\sim 100 \mathrm{ng}$ DNA by transformation and propagation in XL-1 Red competent Escherichia coli (Stratagene), according to the manufacturer's recommendations. Plasmid DNA was isolated using Nucleobond Xtra Midi kit (Takara Bio Inc.). For retrovirus production, we co-transfected the mutagenized JAK2 R683G cDNA library and the retroviral packaging construct pEcoPack (Takara Bio Inc.) at a 1:1 ratio into $293 \mathrm{~T}$ cells using Lipofectamine 2000 (Invitrogen). After $48 \mathrm{~h}$, we harvested the supernatant, passed it through a $0.45-\mu \mathrm{m}$ filter (Millex; Millipore), and transduced $30 \times 10^{6}$ IL-3-dependent Ba/F3 cells that stably express CRLF2 $2_{\text {puro }} /$ IL7R-GFP. After $1 \mathrm{~d}$, we washed the cells and resuspended them in fresh IL-3-containing media substituted with puromycin $1 \mu \mathrm{g} / \mathrm{ml}$ (Sigma-Aldrich). After another day, we changed media to no IL-3 and added $1 \mathrm{mg} / \mathrm{ml}$ neomycin (G418; Gold Biotechnology). Cells were then plated onto 96- or 384-well plates in the presence or absence of $1 \mu \mathrm{M}$ BVB808. Clones that survived BVB808 treatment were expanded in fresh RPMI 1640 media in the presence of puromycin/ neomycin/BVB808 and the absence of IL-3. We isolated genomic DNA using QIAamp DNA Blood Mini kit (QIAGEN) and amplified cDNA in pMSCV $_{\text {puro }}$ att using the following primers: forward primer $5^{\prime}$-TCCTCCCTTTATCCAGCCCTCACTCCTTCTCTAGG-3', reverse primer 5'-CTAAAGCGCATGCTCCAGACTGCCTTGGGAAAAGC-3'.

PCR products were recloned into retroviral expression vector using Gateway BP/LR Cloning System (Invitrogen), and the ability to confer BVB808 resistance was confirmed by transduction and selection in CRLF2 ${ }_{\text {puro }} /$ IL7R-GFP-expressing Ba/F3. cDNA inserts from resistant clones were then PCR amplified and Sanger sequenced (full length) at the Dana Farber Cancer Institute Molecular Biology Core Facilities or the DF/HCC DNA Sequencing Facility. Site-directed mutagenesis was performed using the QuikChange II XL site-directed mutagenesis kit (Stratagene). Each mutant allele was confirmed by sequencing, introduced into $H A-h J A K 2 \mathrm{pMSCV}_{\text {neo }}$ att constructs, and then transduced into the appropriate $\mathrm{Ba} / \mathrm{F} 3$ background. Stably transduced cells were tested for expression of JAK2 by immunoblotting for hemagglutinin (mouse anti-HA; Covance).

siRNA knockdown. IL-3-independent Ba/F3-EpoR cells expressing Jak2 V617F (MSCV-IRES-GFP) with or without E864K, Y931C, or G935R were transfected with either nontargeting control siRNA (siGENOME Non-Targeting siRNA \#3) or siRNA against mouse Jak2 (siGENOME siRNA JAK2) by nucleofection (Cell Line Nucleofector kit V; Lonza) according to the manufacturer's recommendation (X-001 program optimized for $\mathrm{Ba} / \mathrm{F} 3$ cells). Per reaction 1-2 $\times 10^{6}$ cells were resuspended in Nucleofector Solution V in the presence of 150-300 nM siRNA. For Western blot analysis, two reactions were pooled and a third reaction was used for functional assays (CellTiter-Glo Luminescent Cell Viability Assay; Promega). Ba/F3 cells expressing an oncogenic ALK rearrangement (ATIC-ALK) were used as a control for JAK2-independent growth in non-IL-3-containing media. Results from this siRNA knockdown experiment were confirmed in three independent experiments.

Immunoblotting. Cells grown at $0.5 \times 10^{6} / \mathrm{ml}$ were harvested after indicated treatment, washed in PBS, and collected in RIPA lysis buffer (Sigma-Aldrich) containing Protease Inhibitor (Sigma-Aldrich). Protein concentrations were determined by the BCA method (Thermo Fisher Scientific) and equal amounts were loaded onto precast 4-12\% NuPAGE gels (Invitrogen). Western blotting was performed with appropriate dilutions of primary and secondary antibody. Antibodies were directed against tubulin (T9026; Sigma-Aldrich), HA (MMS-101P; Covance), HSP70 (4876S; Cell Signaling Technology), CRLF2 (R\&D Systems), STAT5 (SC-835; Santa Cruz Biotechnology, Inc.), phospho-STAT5 (4322; Cell Signaling Technology), JAK2 (32305; Cell Signaling Technology), phospho-JAK2 (3776S; Cell Signaling Technology), AKT (4691S; Cell Signaling Technology), phospho-AKT (4060S; Cell Signaling Technology), ERK1/2 (4695B; Cell Signaling Technology), phospho-ERK1/2 (4370S; Cell Signaling Technology), 
STAT1 (SC-346; Santa Cruz Biotechnology, Inc.), and phospho-STAT1 (9167S; Cell Signaling Technology).

In vitro inhibitor assay. Viable cells were plated in white opaque 384-well plates (50 $\mu \mathrm{l} /$ well; Corning) using EL406 Combination Washer Dispenser (BioTek) at a density of $0.01-0.05 \times 10^{6}$ cells $/ \mathrm{ml}(\mathrm{Ba} / \mathrm{F} 3)$ and $0.25 \times 10^{6} \mathrm{cells} / \mathrm{ml}$ (MUTZ-5 and MHH-CALL4). Inhibitors or vehicle (DMSO) were added using a JANUS Automated Workstation (PerkinElmer). After 48 h (Ba/F3 cells) or $96 \mathrm{~h}$ (Mutz-5 and MHH-CALL4), CellTiter-Glo Luminescent Cell Viability Assay was added $(25 \mu \mathrm{l}$ each well) and read by the 2104 EnVision Multilabel Reader (PerkinElmer). Each data point was quantified in quadruplicate and experiments were repeated at least twice. Analysis of pairwise dose-response data and isobologram plots was done according to the median-effect principle of Chou and Talalay (1984; CalcuSyn Software). Doseresponse curves and plots were generated with GraphPad Prism software.

Measurement of inhibition of JAK in vitro kinase activity and assessment of antiproliferative activity, as well as biochemical profiling in SET-2, MB-02, UKE-1, MV4;11, CMK and K-562 cell lines was performed as previously described (Baffert et al., 2010)

Competitive growth assay. $\mathrm{Ba} / \mathrm{F} 3-\mathrm{Ep}_{0} \mathrm{R}_{\text {puro }}$ cells were stably transduced with Jak2 V617F (MSCV-Thy1.1) or Jak2 V617F plus one of the three kinase domain mutations (MSCV-IRES-GFP). Cells were mixed at a 1:1 ratio and cultured in media lacking IL-3. In addition, cells were treated with either $1 \mu \mathrm{M}$ BVB808 or $10 \mathrm{nM}$ AUY922. Cells were stained with PE-anti-Thy1.1 (mouse anti-rat CD90.1, clone OX-7; BD) and flow cytometry was performed daily for $3 \mathrm{~d}$ and thereafter as indicated. The viable population was estimated based on forward scatter and side scatter.

In vivo murine experiments. Mouse bone marrow transplants were performed essentially as previously described (James et al., 2005). In brief, female BALB/c mice 8-9 wk of age were lethally irradiated (2 doses of $4.5 \mathrm{~Gy}$ with 4-h interval using the BIOBEAM 8,000 $\gamma$ irradiator), and then transplanted with $3 \times 10^{6}$ donor bone marrow cells (injected i.v. into the tail vein in a total volume of $200 \mu \mathrm{l}$ HPBS, $\mathrm{pH}$ 7.4) that had been transduced with pMSCV Jak2 V617F-IRES-GFP retrovirus. Complete blood counts (CBC) were typically determined 4-6 wk after transplant using a blood analyzer (Sysmex XT-2000i), and mice were randomized into treatment groups based on hematocrit. Dosing with vehicle or $50 \mathrm{mg} / \mathrm{kg}$ BVB 808 by oral gavage twice daily was initiated the following day.

After 3 wk of dosing, animals were given a final dose and sacrificed 2 or $12 \mathrm{~h}$ later for analyses. Sterna and femurs were removed en bloc, fixed for $48 \mathrm{~h}$ in 10\% neutral-buffered formalin at room temperature, and then washed in PBS and decalcified in EDTA-citric acid buffer, $\mathrm{pH} 7.5$, (Biocyc GmbH) for $3 \times 24 \mathrm{~h}$ at $37^{\circ} \mathrm{C}$. After a last wash in PBS, the tissues were cut up and placed with the surface of interest facing downward into a universal histocassette, followed by processing in a TPC 15Duo (Tissue Processing Center) for paraffinization. Spleen samples were processed for histology and pStat5 immunohistochemistry as previously described (Baffert et al., 2010). Animals were kept under $\mathrm{OHC}$ conditions with free access to food and water. These experiments were performed in strict adherence to the Swiss Law for Animal Welfare and approved by the Swiss Cantonal Veterinary Office of Basel-Stadt.

Transplantation of luciferized Ba/F3 cells into nude mice and monitoring of luciferase activity was performed as previously described (Weisberg et al., 2007). In brief, male NCr-nude mice (5-6 wk of age; Taconic) were given a mixture of 1,000,000 VF-Thy1.1-luc ${ }^{+}$cells and 1,000,000 VF-GFP-luc ${ }^{+}$ cells by tail vein injection. Baseline imaging was performed to establish bioluminescence (day 4), and then mice were randomly divided into treatment cohorts (vehicle vs. AUY922). Imaging was done at indicated intervals until day 8 , when the first death occurred. Mice were followed for survival and sacrificed when they developed hind limb paralysis or became moribund.

Two primary human B -ALLs were xenotransplanted into a total of 80 6-wk-old NSG mice. Sample 412 harbors a CRLF2/IgH translocation and a JAK2 R683S mutation. Sample 537 harbors a $P 2 R Y 8-C R L F 2$ rearrangement and lacks a somatic mutation within the known components of CRLF2 signaling, including IL7R, CRLF2, TSLP, JAK1, JAK2, and STAT5A/B.
Mice were injected with primary 412 or 537 cells i.v. via the lateral tail vein without prior irradiation. Full hematologic analysis was performed on 1 mouse from each group every $2 \mathrm{wk}$, with the presence of human leukemia cells detected using a human-specific anti-CD45 antibody. When leukemia was established with bone marrow blasts $>30 \%$, mice were divided into 4 treatment groups: AUY922 (50mg/kg i.v. thrice weekly), BVB808 $(50 \mathrm{mg} / \mathrm{kg}$ by gastric lavage twice daily), combination, and vehicle. The BVB808 regimen was based on efficacy against JAK2 V617F-driven myeloproliferation (Fig. 1, H-J). The AUY922 regimen was based on preclinical studies in a breast cancer xenograft model (Jensen et al., 2008). 3 wk after starting treatment with AUY922 alone or in combination, AUY922 administration was switched to intraperitoneal because of scarring of the lateral tail vein with the same dose and schedule. Mice were sacrificed when they developed hind limb paralysis or became moribund.

To assess the pharmacodynamic efficacy of treatments, a separate cohort of mice were analyzed after $5 \mathrm{~d}$ of treatment. $2-4 \mathrm{~h}$ after the last dose, mice were euthanized and tissues fixed by perfusion with $10 \%$ formalin. Spleen, femur, and liver were collected and further fixed in 10\% neutral-buffered formalin for immunohistochemistry, Western blotting, and isolation of nucleic acids.

These animal studies were performed under Dana Farber Cancer Center Animal Care and Use Committee approved protocols.

$\mathrm{X}$-ray micro-CT imaging. Using the micro-CT on a multimodality preclinical imaging system (Inveon: Siemens Healthcare), longitudinal x-ray computed tomography (CT) scans were performed for a subgroup of mice $(n=7)$ used in this study, to follow their spleen sizes in vivo (and excluded from other analyses). For improving spleen visualization and quantification accuracy, each mouse was injected (i.v. $\sim 70 \mu \mathrm{l}$ ) with a nanoparticle CT contrast agent (Viscover ExiTron nano 12000; Miltenyi Biotec) a few hours before the first (baseline) CT scan. Subsequent scans ( $3 \mathrm{~d}, 1 \mathrm{wk}, 2 \mathrm{wk}$, and $\sim 7 \mathrm{wk}$ after baseline) required no reinjections. At each time point, the mice were first anesthetized by inhalation of a mixture of sevoflurane and medical air, and then underwent a previously established CT imaging protocol $(80 \mathrm{kVp}$, $0.5 \mathrm{~mA}, 220$ degree rotation, $1 \mathrm{~s} /$ degree exposure, $80 \mu \mathrm{m}$ reconstruction pixel size).

The reconstructed volumetric CT data were visualized and analyzed using Amira (version 5.3.3; Visage Imaging). Because ExiTron nano accumulates in liver and spleen, resulting in good image contrasts between these organs and adjacent soft tissues, a threshold-based semiautomatic method available in Amira was used for spleen segmentation. In the occasional events where the boundaries between the liver and spleen were not properly detected, manual delineations were also used. All segmentations were visually confirmed for anatomical consistencies through three-dimensional volume renderings, after which the spleen volumes were automatically calculated by the software. Immediately after the last imaging time point, the spleen in each mouse was exercised and weighed. A simple linear regression analysis was performed between the spleen volumes measured by CT and the weights measured.

Gene expression profiling, differential analysis, and GSEA. MUTZ-5 and MHH-CALL 4 cells grown at a concentration of $10^{6}$ cells $/ \mathrm{ml}$ were treated with vehicle (DMSO), JAKinh-1 $(1 \mu \mathrm{M})$, AUY922 $(50 \mathrm{nM})$, or the combination of both for $14 \mathrm{~h}$, each in triplicate. Total RNA was isolated using TRIzol reagent (Invitrogen). RNA was also isolated from mouse bone marrow infiltrated by human CRLF2-rearranged leukemia primary xenografts 412 and 537 after $5 \mathrm{~d}$ of treatment with BVB808, AUY922, the combination, or vehicle, as outlined above. Hematoxylin and eosin staining and immunohistochemistry with anti-hCD45 antibody demonstrated $>80 \%$ tumor cell infiltration in all samples.

RNA was hybridized to Affymetrix U133_Plus2 chips at the Dana Farber Cancer Center Microarray Core. All analyses were performed using Gene Pattern (Broad Institute, http://www.broadinstitute.org/cancer/ software/genepattern; Reich et al., 2006). Raw probe-level data from Affymetrix .CEL files were summarized using the Robust Multiarray Average (RMA) procedure available through the ExpressionFileCreator module in Gene Pattern. Using the preprocessing module, a variation filter was 
applied (threefold minimum change and 100 minimum absolute difference) and values were thresholded at 10, leaving 11,751 probes representing 6,720 genes in the dataset. After $\log 2$ transformation a differential analysis of markers in the union of cell lines between different treatment conditions (union of all cell lines treated with the same drug) and vehicle was performed using the comparative marker selection module. For visualization up to 20 most differentially expressed probes were selected based on an FDR q-value $<0.25$ and a fold change $>2.5$. Visualization and hierarchical clustering of probes using Pearson correlation was done with GEN-E software (Broad Institute; http://www.broadinstitute.org/cancer/software/GENE-E/dev/).

The JAK inhibitor signature was defined to encompass the top and bottom 250 most differentially expressed genes between vehicle (DMSO) and JAKinh-1. The JAK inhibitor signature was subsequently tested for enrichment in the DMSO versus AUY922 group using the GSEA method as previously described (http://www.broadinstitute.org/gsea/index.jsp; Subramanian et al., 2005). To capture common transcription factor binding motifs within the most differentially expressed genes between the DMSO and AUY922 treatment arm GSEA was performed with the publically available C3-transcription factor site database from the MsigDB repository (Broad Institute, http://www.broadinstitute.org/gsea/msigdb/index.jsp5, (Subramanian et al., 2005). Subsequently, GSEA was performed for each treatment condition using the predefined gene sets for either STAT5A (V\$STAT5A_01, V\$STAT5A_02, V\$STAT5A_03, V\$STAT5A_04) and HSF1 (RGAANNTTC_V\$HSF1_01), from the publically available pathway repository MSigDB (Broad Institute; http://www.broadinstitute.org/ gsea/msigdb/index.jsp5).

Online supplemental material. Supplementary information for this study includes information on $\mathrm{IC}_{50}$ concentrations for JAK enzymatic inhibitors and HSP90 inhibitors in Ba/F3 cell lines (Table S1), previous studies describing JAK2 mutations that confer resistance to enzymatic inhibitors (Table S2), most differentially regulated genes in MHH-CALL4 and MUTZ-5 cells upon treatment with inhibitors (Table S3), and BVB808 pharmacokinetics (Fig. S1). Online supplemental material is available at http://www.jem.org/ cgi/content/full/jem.20111694/DC1.

The authors thank Ed Fox and Terry Haley for assistance with next-generation sequencing, Margaret Shipp for assistance with transcriptional profiling analysis, and Jim Griffin and Patrick Chène for thoughtful comments. We thank Gabriela Chiosis for providing PU-H71, and Joëlle Rubert, Zhiyan Qian, Rita Andraos, Fanny Marque, Frédéric Baysang, Violetta Powajbo, and Hughes Ryckelynck for excellent technical assistance.

0 . Weigert is supported by the Deutsche Forschungsgemeinschaft. This work was supported by NCl 1R01CA151898-01 (D.M. Weinstock) and the DFCI/Novartis Drug Discovery Program (D.M. Weinstock).

C. Gaul, E. Vangrevelinghe, V. Romanet, M. Murakami, R. Teidt, N. Ebel, E. Evrot, A. De Pover, C.H. Régnier, D. Erdmann, F. Hofmann, F. Baffert, and T. Radimerski are employed by the Novartis Institute for Biomedical Research. M.J. Eck, A.L. Kung, and D.M. Weinstock are paid consultants and receive research support from Novartis.

\section{Submitted: 24 June 2011}

Accepted: 9 January 2012

\section{REFERENCES}

Abramson, J.S., W. Chen, P. Juszczynski, H. Takahashi, D. Neuberg, J.L. Kutok, K. Takeyama, and M.A. Shipp. 2009. The heat shock protein 90 inhibitor IPI-504 induces apoptosis of AKT-dependent diffuse large B-cell lymphomas. Br. J. Haematol. 144:358-366. http://dx.doi.org/10.1111/ j.1365-2141.2008.07484.x

Azam, M., R.R. Latek, and G.Q. Daley. 2003. Mechanisms of autoinhibition and STI-571/imatinib resistance revealed by mutagenesis of BCR-ABL. Cell. 112:831-843. http://dx.doi.org/10.1016/S0092-8674(03)00190-9

Baffert, F., C.H. Régnier, A. De Pover, C. Pissot-Soldermann, G.A. Tavares, F. Blasco, J. Brueggen, P. Chène, P. Drueckes, D. Erdmann, et al. 2010. Potent and selective inhibition of polycythemia by the quinoxaline JAK2 inhibitor NVP-BSK805. Mol. Cancer Ther. 9:1945-1955. http://dx.doi.org/10.1158/1535-7163.MCT-10-0053
Bareng, J., I. Jilani, M. Gorre, H. Kantarjian, F. Giles, A. Hannah, and M. Albitar. 2007. A potential role for HSP90 inhibitors in the treatment of JAK2 mutant-positive diseases as demonstrated using quantitative flow cytometry. Leuk. Lymphoma. 48:2189-2195. http://dx.doi.org/10 $.1080 / 10428190701607576$

Cerchietti, L.C., E.C. Lopes, S.N. Yang, K. Hatzi, K.L. Bunting, L.A. Tsikitas, A. Mallik, A.I. Robles, J. Walling, L. Varticovski, et al. 2009. A purine scaffold Hsp90 inhibitor destabilizes BCL-6 and has specific antitumor activity in BCL-6-dependent B cell lymphomas. Nat. Med. 15:1369-1376. http://dx.doi.org/10.1038/nm.2059

Chou, T.C., and P. Talalay. 1984. Quantitative analysis of dose-effect relationships: the combined effects of multiple drugs or enzyme inhibitors. $A d v$. Enzyme Regul. 22:27-55. http://dx.doi.org/10.1016/0065-2571(84) 90007-4

Druker, B.J., C.L. Sawyers, H. Kantarjian, D.J. Resta, S.F. Reese, J.M. Ford, R. Capdeville, and M. Talpaz. 2001. Activity of a specific inhibitor of the BCR-ABL tyrosine kinase in the blast crisis of chronic myeloid leukemia and acute lymphoblastic leukemia with the Philadelphia chromosome. N. Engl. J. Med. 344:1038-1042. http://dx.doi.org/10 .1056/NEJM200104053441402

Eccles, S.A., A. Massey, F.I. Raynaud, S.Y. Sharp, G. Box, M. Valenti, L. Patterson, A. de Haven Brandon, S. Gowan, F. Boxall, et al. 2008 NVP-AUY922: a novel heat shock protein 90 inhibitor active against xenograft tumor growth, angiogenesis, and metastasis. Cancer Res. 68:2850-2860. http://dx.doi.org/10.1158/0008-5472.CAN-07-5256

Engelman, J.A., and J. Settleman. 2008. Acquired resistance to tyrosine kinase inhibitors during cancer therapy. Curr. Opin. Genet. Dev. 18:73-79. http:// dx.doi.org/10.1016/j.gde.2008.01.004

Flaherty, K.T., I. Puzanov, K.B. Kim, A. Ribas, G.A. McArthur, J.A. Sosman, P.J. O'Dwyer, R.J. Lee, J.F. Grippo, K. Nolop, and P.B. Chapman. 2010. Inhibition of mutated, activated BRAF in metastatic melanoma. N. Engl. J. Med. 363:809-819. http://dx.doi.org/10.1056/ NEJMoa1002011

Grandage, V.L., T. Everington, D.C. Linch, and A. Khwaja. 2006. Gö6976 is a potent inhibitor of the JAK 2 and FLT3 tyrosine kinases with significant activity in primary acute myeloid leukaemia cells. Br. J. Haematol. 135:303-316. http://dx.doi.org/10.1111/j.1365-2141.2006.06291.x

Green, M.R., S. Monti, S.J. Rodig, P. Juszczynski, T. Currie, E. O'Donnell, B. Chapuy, K. Takeyama, D. Neuberg, T.R. Golub, et al. 2010. Integrative analysis reveals selective 9p24.1 amplification, increased PD-1 ligand expression, and further induction via JAK2 in nodular sclerosing Hodgkin lymphoma and primary mediastinal large B-cell lymphoma. Blood. 116:3268-3277. http://dx.doi.org/10.1182/blood-2010-05-282780

Griswold, I.J., M. MacPartlin, T. Bumm, V.L. Goss, T. O'Hare, K.A. Lee, A.S. Corbin, E.P. Stoffregen, C. Smith, K. Johnson, et al. 2006. Kinase domain mutants of Bcr-Abl exhibit altered transformation potency, kinase activity, and substrate utilization, irrespective of sensitivity to imatinib. Mol. Cell. Biol. 26:6082-6093. http://dx.doi.org/10.1128/MCB.02202-05

Haan, S., S. Wüller, J. Kaczor, C. Rolvering, T. Nöcker, I. Behrmann, and C. Haan. 2009. SOCS-mediated downregulation of mutant Jak2 (V617F, T875N and K539L) counteracts cytokine-independent signaling. Oncogene. 28:3069-3080. http://dx.doi.org/10.1038/onc.2009.155

Hart, S., K.C. Goh, V. Novotny-Diermayr, C.Y. Hu, H. Hentze, Y.C. Tan, B. Madan, C. Amalini, Y.K. Loh, L.C. Ong, A.D. William, A. Lee, A. Poulsen, R. Jayaraman, K.H. Ong, K. Ethirajulu, B.W. Dymock, and J.W. Wood. 2011. SB1518, a novel macrocyclic pyrimidine-based JAK2 inhibitor for the treatment of myeloid and lymphoid malignancies. Leukemia

Harvey, R.C., C.G. Mullighan, I.M. Chen, W. Wharton, F.M. Mikhail, A.J. Carroll, H. Kang, W. Liu, K.K. Dobbin, M.A. Smith, et al. 2010. Rearrangement of CRLF2 is associated with mutation of JAK kinases, alteration of IKZF1, Hispanic/Latino ethnicity, and a poor outcome in pediatric B-progenitor acute lymphoblastic leukemia. Blood. 115:53125321. http://dx.doi.org/10.1182/blood-2009-09-245944

Hertzberg, L., E. Vendramini, I. Ganmore, G. Cazzaniga, M. Schmitz, J. Chalker, R. Shiloh, I. Iacobucci, C. Shochat, S. Zeligson, et al. 2010. Down syndrome acute lymphoblastic leukemia, a highly heterogeneous disease in which aberrant expression of CRLF2 is associated with mutated JAK2: a report from the International BFM Study Group. Blood. 115:1006-1017. http://dx.doi.org/10.1182/blood-2009-08-235408 
Ihle, J.N., and D.G. Gilliland. 2007. Jak2: normal function and role in hematopoietic disorders. Curr. Opin. Genet. Dev. 17:8-14. http://dx.doi.org/ 10.1016/j.gde.2006.12.009

James, C., V. Ugo, J.P. Le Couédic, J. Staerk, F. Delhommeau, C. Lacout, L. Garçon, H. Raslova, R. Berger, A. Bennaceur-Griscelli, et al. 2005. A unique clonal JAK2 mutation leading to constitutive signalling causes polycythaemia vera. Nature. 434:1144-1148. http://dx.doi.org/10.1038/ nature 03546

Jensen, M.R., J. Schoepfer, T. Radimerski, A. Massey, C.T. Guy, J. Brueggen, C. Quadt, A. Buckler, R. Cozens, M.J. Drysdale, et al. 2008. NVP-AUY922: a small molecule HSP90 inhibitor with potent antitumor activity in preclinical breast cancer models. Breast Cancer Res. 10:R33. http://dx.doi.org/10.1186/bcr1996

Joensuu, H., P.J. Roberts, M. Sarlomo-Rikala, L.C. Andersson, P. Tervahartiala, D. Tuveson, S. Silberman, R. Capdeville, S. Dimitrijevic, B. Druker, and G.D. Demetri. 2001. Effect of the tyrosine kinase inhibitor STI571 in a patient with a metastatic gastrointestinal stromal tumor. N. Engl. J. Med. 344:1052-1056. http://dx.doi.org/10.1056/NEJM200104053441404

Kiss, R., P.P. Sayeski, and G.M. Keserũ. 2010. Recent developments on JAK2 inhibitors: a patent review. Expert Opin Ther Pat. 20:471-495. http://dx.doi.org/10.1517/13543771003639436

Levine, R.L., M. Wadleigh, J. Cools, B.L. Ebert, G. Wernig, B.J. Huntly, T.J. Boggon, I. Wlodarska, J.J. Clark, S. Moore, et al. 2005. Activating mutation in the tyrosine kinase JAK2 in polycythemia vera, essential thrombocythemia, and myeloid metaplasia with myelofibrosis. Cancer Cell. 7:387-397. http://dx.doi.org/10.1016/j.ccr.2005.03.023

Levine, R.L., A. Pardanani, A. Tefferi, and D.G. Gilliland. 2007. Role of JAK2 in the pathogenesis and therapy of myeloproliferative disorders. Nat. Rev. Cancer. 7:673-683. http://dx.doi.org/10.1038/nrc2210

Levy, D.S., J.A. Kahana, and R. Kumar. 2009. AKT inhibitor, GSK690693, induces growth inhibition and apoptosis in acute lymphoblastic leukemia cell lines. Blood. 113:1723-1729. http://dx.doi.org/10.1182/blood-2008-02137737

Lucet, I.S., E. Fantino, M. Styles, R. Bamert, O. Patel, S.E. Broughton, M. Walter, C.J. Burns, H. Treutlein, A.F. Wilks, and J. Rossjohn. 2006. The structural basis of Janus kinase 2 inhibition by a potent and specific panJanus kinase inhibitor. Blood. 107:176-183. http://dx.doi.org/10.1182/ blood-2005-06-2413

Manshouri, T., A. Quintás-Cardama, R.H. Nussenzveig, A. Gaikwad, Z. Estrov, J. Prchal, J.E. Cortes, H.M. Kantarjian, and S. Verstovsek. 2008. The JAK kinase inhibitor CP-690,550 suppresses the growth of human polycythemia vera cells carrying the JAK2V617F mutation. Cancer Sci. 99:1265-1273. http://dx.doi.org/10.1111/j.1349-7006.2008.00817.x

Marotta, L.L., V. Almendro, A. Marusyk, M. Shipitsin, J. Schemme, S.R. Walker, N. Bloushtain-Qimron, J.J. Kim, S.A. Choudhury, R. Maruyama, et al. 2011. The JAK2/STAT3 signaling pathway is required for growth of CD $44^{+} \mathrm{CD} 24^{-}$stem cell-like breast cancer cells in human tumors. J. Clin. Invest. 121:2723-2735. http://dx.doi.org/10.1172/ JCI44745

Marubayashi, S., P. Koppikar, T. Taldone, O. Abdel-Wahab, N. West, N. Bhagwat, E. Caldas-Lopes, K.N. Ross, M. Gönen, A. Gozman, et al. 2010. HSP90 is a therapeutic target in JAK2-dependent myeloproliferative neoplasms in mice and humans. J. Clin. Invest. 120:3578-3593. http://dx.doi.org/10.1172/JCI42442

Mullighan, C.G., J.R. Collins-Underwood, L.A. Phillips, M.G. Loudin, W. Liu, J. Zhang, J. Ma, E. Coustan-Smith, R.C. Harvey, C.L. Willman, et al. 2009a. Rearrangement of CRLF2 in B-progenitor- and Down syndromeassociated acute lymphoblastic leukemia. Nat. Genet. 41:1243-1246. http://dx.doi.org/10.1038/ng.469

Mullighan, C.G., J. Zhang, R.C. Harvey, J.R. Collins-Underwood, B.A. Schulman, L.A. Phillips, S.K. Tasian, M.L. Loh, X. Su, W.Liu, etal. 2009b. JAK mutations in high-risk childhood acute lymphoblastic leukemia. Proc. Natl. Acad. Sci. USA. 106:9414-9418. http://dx.doi.org/10.1073/ pnas.0811761106

Najfeld, V., A. Cozza, W. Berkofsy-Fessler, J. Prchal, and A. Scalise. 2007. Numerical gain and structural rearrangements of JAK2, identified by FISH, characterize both JAK2617V $>$ F-positive and -negative patients with Phnegative MPD, myelodysplasia, and B-lymphoid neoplasms. Exp. Hematol. 35:1668-1676. http://dx.doi.org/10.1016/j.exphem.2007.08.025
Neckers, L. 2007. Heat shock protein 90: the cancer chaperone. J. Biosci. 32:517-530. http://dx.doi.org/10.1007/s12038-007-0051-y

Pardanani, A. 2008. JAK2 inhibitor therapy in myeloproliferative disorders: rationale, preclinical studies and ongoing clinical trials. Leukemia. 22:2330. http://dx.doi.org/10.1038/sj.leu.2404948

Pardanani, A., J.R. Gotlib, C. Jamieson, J.E. Cortes, M. Talpaz, R.M. Stone, M.H. Silverman, D.G. Gilliland, J. Shorr, and A. Tefferi. 2011. Safety and efficacy of TG101348, a selective JAK2 inhibitor, in myelofibrosis. $J$. Clin. Oncol. 29:789-796. http://dx.doi.org/10.1200/JCO.2010.32.8021

Pikman, Y., B.H. Lee, T. Mercher, E. McDowell, B.L. Ebert, M. Gozo, A. Cuker, G. Wernig, S. Moore, I. Galinsky, et al. 2006. MPLW515L is a novel somatic activating mutation in myelofibrosis with myeloid metaplasia. PLoS Med. 3:e270. http://dx.doi.org/10.1371/journal.pmed.0030270

Proia, D.A., K.P. Foley, T. Korbut, J. Sang, D. Smith, R.C. Bates, Y. Liu, A.F. Rosenberg, D. Zhou, K. Koya, et al. 2011. Multifaceted intervention by the Hsp90 inhibitor ganetespib (STA-9090) in cancer cells with activated JAK/STAT signaling. PLoS ONE. 6:e18552. http://dx.doi.org/10.1371/ journal.pone.0018552

Reich, M., T. Liefeld, J. Gould, J. Lerner, P. Tamayo, and J.P. Mesirov. 2006. GenePattern 2.0. Nat. Genet. 38:500-501. http://dx.doi.org/10.1038/ ng0506-500

Richardson, P.G., C.S. Mitsiades, J.P. Laubach, S. Lonial, A.A. ChananKhan, and K.C. Anderson. 2011. Inhibition of heat shock protein 90 (HSP90) as a therapeutic strategy for the treatment of myeloma and other cancers. Br. J. Haematol. 152:367-379. http://dx.doi.org/10.1111/ j.1365-2141.2010.08360.x

Rui, L., N.C. Emre, M.J. Kruhlak, H.J. Chung, C. Steidl, G. Slack, G.W. Wright, G. Lenz, V.N. Ngo, A.L. Shaffer, et al. 2010. Cooperative epigenetic modulation by cancer amplicon genes. Cancer Cell. 18:590-605. http://dx.doi.org/10.1016/j.ccr.2010.11.013

Russell, L.J., M. Capasso, I. Vater, T. Akasaka, O.A. Bernard, M.J. Calasanz, T. Chandrasekaran, E. Chapiro, S. Gesk, M. Griffiths, et al. 2009. Deregulated expression of cytokine receptor gene, CRLF2, is involved in lymphoid transformation in B-cell precursor acute lymphoblastic leukemia. Blood. 114:2688-2698. http://dx.doi.org/10.1182/blood-2009-03-208397

Sanda, T., X. Li, A. Gutierrez, Y. Ahn, D.S. Neuberg, J. O’Neil, P.R. Strack, C.G. Winter, S.S. Winter, R.S. Larson, et al. 2010. Interconnecting molecular pathways in the pathogenesis and drug sensitivity of T-cell acute lymphoblastic leukemia. Blood. 115:1735-1745. http://dx.doi.org/ 10.1182/blood-2009-07-235143

Shochat, C., N. Tal, O.R. Bandapalli, C. Palmi, I. Ganmore, G. te Kronnie, G. Cario, G. Cazzaniga, A.E. Kulozik, M. Stanulla, et al. 2011. Gain-of-function mutations in interleukin-7 receptor- $\alpha$ (IL7R) in childhood acute lymphoblastic leukemias. J. Exp. Med. 208:901-908. http://dx.doi.org/10.1084/ jem. 20110580

Soverini, S., A. Hochhaus, F.E. Nicolini, F. Gruber, T. Lange, G. Saglio, F. Pane, M.C. Muller, T. Ernst, G. Rosti, K. Porkka, M. Baccarani, N.C Cross, and G. Martinelli. 2011. Bcr-Abl kinase domain mutation analysis in chronic myeloid leukemia patients treated with tyrosine kinase inhibitors: recommendations from an expert panel on behalf of European LeukemiaNet. Blood

Stühmer, T., A. Zöllinger, D. Siegmund, M. Chatterjee, E. Grella, S. Knop, M. Kortüm, C. Unzicker, M.R. Jensen, C. Quadt, et al. 2008. Signalling profile and antitumour activity of the novel Hsp90 inhibitor NVP-AUY922 in multiple myeloma. Leukemia. 22:1604-1612. http:// dx.doi.org/10.1038/leu.2008.111

Subramanian, A., P. Tamayo, V.K. Mootha, S. Mukherjee, B.L. Ebert, M.A. Gillette, A. Paulovich, S.L. Pomeroy, T.R. Golub, E.S. Lander, and J.P. Mesirov. 2005. Gene set enrichment analysis: a knowledge-based approach for interpreting genome-wide expression profiles. Proc. Natl. Acad. Sci. USA. 102:15545-15550. http://dx.doi.org/10.1073/pnas.0506580102

Trepel, J., M. Mollapour, G. Giaccone, and L. Neckers. 2010. Targeting the dynamic HSP90 complex in cancer. Nat. Rev. Cancer. 10:537-549. http://dx.doi.org/10.1038/nrc2887

Verstovsek, S. 2009. Therapeutic potential of JAK2 inhibitors. Hematology Am. Soc. Hematol. Educ. Program 2009:636-642.

Verstovsek, S., H. Kantarjian, R.A. Mesa, A.D. Pardanani, J. Cortes-Franco, D.A. Thomas, Z. Estrov, J.S. Fridman, E.C. Bradley, S. EricksonViitanen, K. Vaddi, R. Levy, and A. Tefferi. 2011. Safety and efficacy of 
INCB018424, a JAK1 and JAK2 inhibitor, in myelofibrosis. N. Engl. J. Med. 363:1117-1127. http://dx.doi.org/10.1056/NEJMoa1002028

Wang, Y., W. Fiskus, D.G. Chong, K.M. Buckley, K. Natarajan, R. Rao, A. Joshi, R. Balusu, S. Koul, J. Chen, et al. 2009. Cotreatment with panobinostat and JAK2 inhibitor TG101209 attenuates JAK2V617F levels and signaling and exerts synergistic cytotoxic effects against human myeloproliferative neoplastic cells. Blood. 114:5024-5033. http://dx.doi.org/10 .1182/blood-2009-05-222133

Wardrop, D., and D.P. Steensma. 2009. Is refractory anaemia with ring sideroblasts and thrombocytosis (RARS-T) a necessary or useful diagnostic category? Br. J. Haematol. 144:809-817. http://dx.doi.org/10.1111/j.13652141.2008.07526.x

Weisberg, E., A.L. Kung, R.D. Wright, D. Moreno, L. Catley, A. Ray, L. Zawel, M. Tran, J. Cools, G. Gilliland, et al. 2007. Potentiation of antileukemic therapies by Smac mimetic, LBW242: effects on mutant
FLT3-expressing cells. Mol. Cancer Ther. 6:1951-1961. http://dx.doi.org/ 10.1158/1535-7163.MCT-06-0810

Wernig, G., M.G. Kharas, R. Okabe, S.A. Moore, D.S. Leeman, D.E. Cullen, M. Gozo, E.P. McDowell, R.L. Levine, J. Doukas, et al. 2008. Efficacy of TG101348, a selective JAK2 inhibitor, in treatment of a murine model of JAK2V617F-induced polycythemia vera. Cancer Cell. 13:311-320. http://dx.doi.org/10.1016/j.ccr.2008.02.009

Yoda, A., Y. Yoda, S. Chiaretti, M. Bar-Natan, K. Mani, S.J. Rodig, N. West, Y Xiao, J.R. Brown, C. Mitsiades, et al. 2010. Functional screening identifies CRLF2 in precursor B-cell acute lymphoblastic leukemia. Proc. Natl. Acad. Sci. USA. 107:252-257. http://dx.doi.org/10.1073/pnas.0911726107

Zhou, W., W. Hur, U. McDermott, A. Dutt, W. Xian, S.B. Ficarro, J. Zhang, S.V. Sharma, J. Brugge, M. Meyerson, et al. 2010. A structure-guided approach to creating covalent FGFR inhibitors. Chem. Biol. 17:285-295. http://dx.doi.org/10.1016/j.chembiol.2010.02.007 